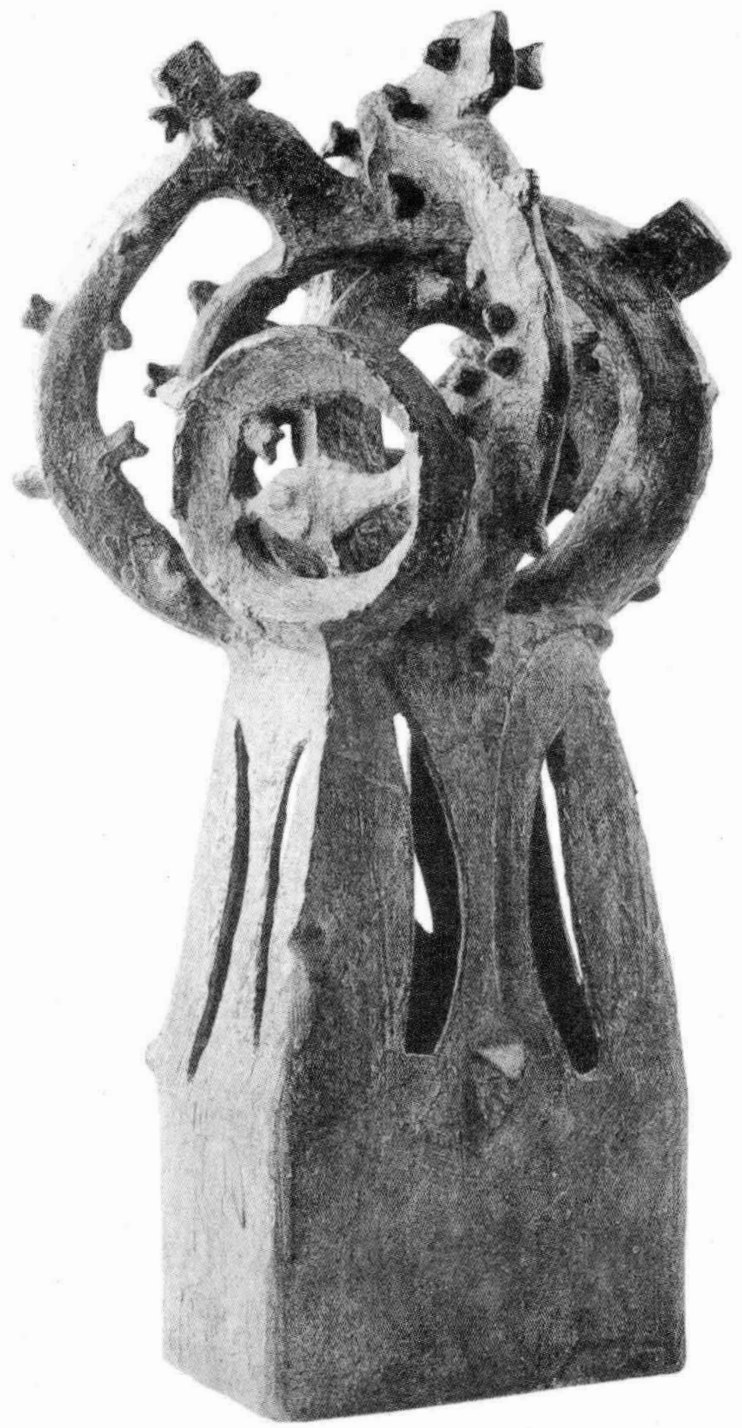




\section{José Luis Grosso}

Profesor del Instituto de Educación y Pedagogía de la Universidad del Valle, Santiago de Cali, Colombia. Pertenece al Grupo de Investigación Educación Popular. Doctor en Antropología Social, Univesidade de Brasilia, Brasilia, Brasil. Maestro en Historia Andina, FuAcso-Universidad del Valle, Santiago de Cali, Colombia. Profesor licenciado en Filosofía, Universidad del Salvador, Buenos Aires, Argentina. Entre sus publicaciones más recientes se encuentran: Antigona. Hija, bermana, mujer, Instituto Departamental de Bellas Artes, Santiago de Cali, 2003; Una modernidad social inaudita e invisible en la trama intercultural latinoamericano-caribeña en F. López Segrera, J. L. Grosso, A. Didriksson y F. J. Mojica (coords.), América Latina y el Caribe en el siglo XXI. Perspectiva y prospectiva de la globalización, Miguel Ángel Porrúa, México, 2004.

\section{Resumen}

Este artículo hace un recorrido por diversas literaturas y textos clave de las ciencias sociales en las últimas décadas, reconstruyendo críticamente la relación con la alteridad que en ellos se tematiza, y propone un desplazamiento de la figuración poética a la representación dramática en el marco programático de una semiología de las prácticas como teoría crítica en contextos poscoloniales.

Palabras clave:

Alteridad, poética de la representación, dramática de la representación, semiología de las prácticas, teoría crítica.

\section{Abstract}

This article surveys various literatures and key social science texts in recent decades, critically reconstructing the relationship with alterity they reflect and proposing a shift from poetic figuration to dramatic representation in the programmatic framework of a semiology of practices as critical theory in post-colonial contexts.

\section{Key words:}

Alterity, poetics of representation, dramatics of representation, semiology of practices, critical theory.

Fecha de recepción: enero de 2005

Fecha de aceptación: mayo de 2005 


\title{
Las labores nocturnas. Hacia una semiología de las prácticas en contextos interculturales poscoloniales
}

\author{
José Luis Grosso*
}

\author{
A Álvaro Morales Torres, \\ primer lector de este texto. \\ In memoriam
}

Q ste texto ha tenido un largo proceso de gestación en el campo científico, académico, y a la vez político, del estudio de los procesos sociales latinoamericanos, y es escrito bajo la obstinada convicción de que la contribución a la transformación social es el quehacer primordial de este campo. La construcción del "otro" ha sido y es una de las escenas críticas de la antropología desde hace varias décadas; algunas de sus producciones son recogidas en estas páginas. Se percibirá en ellas un desplazamiento hacia las prácticas en las que se gesta y se gestiona la relación entre unos y otros. Esta relación es la cuestión crucial, donde la semiología de las prácticas se constituye en teoría social crítica latinoamericana, al traer los sentidos naturalizados en los cuerpos y la acción crítica cotidiana y silenciosa que ellos operan a un nuevo reconocimiento epistemológico. Me propongo desplazar la atención hacia esas prácticas invisibles en la relación pedagógica y en la relación científica (consti-

* Agradezco los comentarios críticos de Jesús González y William López. tutivas de este texto en sus diversas instancias de producción y lectura), que siempre son, en primer lugar, relaciones sociales y políticas.

El escenario inaugural de la "hermenéutica doble"l se abre sobre el dominio de las representaciones de los otros, donde toda interpretación procede de preinterpretaciones: cuerpos encontrados y sentidos en pugna. Debajo y detrás de los dis-

${ }^{1}$ Giddens, Nuevas, 1997. Anthony Giddens ha destacado esta condición, propia de las ciencias sociales, reconocida con mayor o menor consecuencia por varios autores, especialmente desde la reconstrucción fenomenológica de la relación entre conocimiento científico y sentido común (Alfred Schutz; Harold Garfinkel). Tal como lo señala Giddens, "los esquemas conceptuales de las ciencias sociales expresan una bermenéutica doble, que supone penetrar y aprehender los marcos de sentido que intervienen en la producción de la vida social por los actores legos, y reconstruirlos en los nuevos marcos de sentido que intervienen en esquemas técnicos conceptuales", ibid., p. 102; y, a su vez, "así como los científicos sociales adoptan términos corrientes -'sentido', 'motivo', 'poder', etc.y los usan en acepciones especializadas, también los actores legos tienden a apoderarse de conceptos y teorías de las ciencias sociales y a integrarlos como elementos constitutivos en la racionalización de su propia conducta". Ibid., p. 191. "Esta hermenéutica doble es de una considerable complejidad, porque la conexión (entre lenguaje corriente y lenguaje técnico) no esta- 
cursos, crece el fragor de los espectros. Hacia ese fragor dramático, cuerpo a cuerpo intercultural, tramado de historias incontables de imposiciones y luchas, se dirige nuestro poético recorrido. Allí emergen los más oscuros y olvidados rastros de la interculturalidad que nos constituye, y se prolonga nuestra poscolonialidad: la evidencia invisible y el rumor inaudito de nuestro tortuoso "ingreso a la historia" y de nuestro salto tutelado a la "autonomía moderna". El "pos" no es cumplimiento, sino batallas aún en curso, aunque nocturnas: un bullir de narrativas heréticas y de trabajos mundanos, desconocidos.

blece una circulación de sentido único; hay un continuo 'deslizamiento' de los conceptos construidos en sociología, por el cual se apropian de ellos aquellos individuos para el análisis de cuya conducta fueron originalmente acuñados, $y$ así tienden a convertirse en rasgos integrales de esa conducta." Ibid., p. 194. A pesar de que Giddens acentúa la "hermenéutica doble" en la apropiación por parte de los actores sociales del lenguaje científico, que siempre dará lugar a un uso diferencial, cargado de valoraciones socioculturales, al ser incluido en los juegos de lenguaje locales y "deformado" por ellos; sin embargo, no destaca suficientemente que esta condición problemática no debe ser leída unilateralmente desde los intereses cognitivos de los científicos sociales, sino que inscribe radicalmente a la ciencia social en la gestión social del conocimiento y en la materialidad cultural de las relaciones cotidianas, que exceden siempre aquellos intereses cognitivos estrictos (y estrechos) y que muestra a la ciencia social como un recurso dominante, investido de prestigio y superioridad, arrebatado tácticamente por los diversos actores sociales para dicha gestión y en aquellas relaciones. Es allí donde el interés puramente cognitivo, academicista, demarcando su distinción, protege a los sectores dominantes, tradicionales y emergentes, de los cursos no deseados de la transformación social.
EN BUSCA DE LA METÁFORA PERDIDA: EL OTRO FUNDACIONAL DEL EXPANSIONISMO EUROPEO

Aquello que reiteramos en la costumbre ha sido alguna vez un resuelto gesto creador. Quizás este subsuelo sea el terreno donde tiene lugar la construcción de lo que el pensamiento social europeo ha llamado el "sujeto de la historia". Lo que ensayo aquí es poder llegar a dar los contornos de ese bajorrelieve, sumergiendo en esas prácticas oscuras las virtudes del lenguaje. Y lo que en definitiva no es más que una ingeniería reconstructiva ( $o$, más bien, una erosión "deconstructiva") de los cimientos, en el caso del proceso europeo (y tal vez en todos) parece poner en primer lugar de manifiesto la perpetuidad antisísmica de las fundaciones naturalizadas. Por algo Europa ha transportado por el mundo entero, junto coń sus discursos, compulsivamente, su voluntad imperativa de fundar: fundarse a Sí Misma y fundar su "otro" contextual; fundar (antes que nada) los términos de esa relación.

El discurso colonial de la "hospitalidad", omnipresente en la relación europea con los "otros", esconde una imagen previa del Sí Mismo frente a, y sobre, el "otro", naturalizada, universalizada. El discurso de la "hospitalidad" no es más que la justificación callada de una "presencia" europea universal, exclusiva en su necesariedad, excluyente en su necesidad: todos los pueblos deben abrirle paso y acogerla porque en realidad ella no es nada sin ellos, vive para su misión de "alterizarlos" y se alimenta de la percepción de que ellos no son "tan absolutamente" diferentes, sino, en el fondo, tan solamente y sin embargo, sus "otros": aquellos que no tienen en ningún caso más "Sí Mismo" que la 
referencialidad europea fundante. Un monoteísmo que aplasta la relación que habita, un Otro creador ex nibilo que no puede ser sino acogido, el absoluto de un don único y monolítico. Demorémonos en este comienzo abrupto.

Según Hayden White, el discurso ha sido un medio privilegiado de la construcción de la conciencia europea. ${ }^{2}$ Dicho discurso ha sido sometido a estudio en la gramática clásica y escolástica, llegándose a la distinción de cuatro figuras prototípicas y paradigmáticas de su flexibilidad articulatoria, verbal y escrita: metáfora, metonimia, sinécdoque e ironía. Movimientos de desplazamiento de sentido en el lenguaje que constituyen al discurso, y cuya base no es lógica, sino práctica; en todo caso, movimientos fundadores de una lógica. Dichos cuatro movimientos son los así denominados "tropos". Nos hallamos ante un exceso "trópico" del discurso y de su lógica: "Logic itself is merely a formalization of tropical strategies" 3 Del interior del discurso nos vemos desplazados así a la praxis, que lo constituye en cuatro torsiones.

$\mathrm{La}$ "conciencia europea", entonces, se construye en el discurso a través de varios tropos, modelados en cuatro figuras, y por medio de los cuales podríamos acceder a las formulaciones más elementales de aquélla. "La inclusión de lo no familiar dentro de lo familiar es una acción trópica (troping), generalmente figurativa (o 'imaginativa')". ${ }^{4}$ Se trata de una "prefiguración" originaria, la metáfora, que preside otros tres "tropos de figuración", en su se-

${ }^{2}$ White, Tropics, 1978.

3 "La lógica misma es meramente una formalización de estrategias trópicas." Ibid, , p. 6.

${ }^{4}$ Ibid., p. 5. cuencialidad: metonimia, sinécdoque e ironía. En primer lugar, la "metáforica constitución de un dominio de experiencia"; luego, la "dispersión metonímica de los elementos de dicho dominio en series ligadas por relaciones de contigüidad"; a continuación, la "representación sinecdóquica de los atributos superficiales de los elementos dispersos en su presumida esencia a través de un principio ordenador"; y, finalmente, la relativización irónica de lo incluido en dicha representación desde el interés por lo excluido.

Giros metalógicos en medio de la propia lógica (previamente establecida y naturalizada en cada nivel), guiados por el interés de resituar a la conciencia ( $y$ a la configuración de un saber) con respecto a su entorno, de redefinir la distinción entre el sí mismo y el entorno, o de reconceptualizar la relación entre el sí mismo y el otro. ${ }^{5}$

Quedamos así habilitados para tratar de hallar, arqueológicamente y a través de un rastreo histórico, las metáforas inaugurales de la "conciencia europea". Y veremos que, en ellas, el gesto-lenguaje fundacional pone siempre la relación con un "otro", representada bajo un movimiento potencial: una superioridad desplazable y una inferioridad absorbible. Metáforas que hacen parte, por lo tanto, de una dramática: "representación" no sólo en su carácter linguístico (ideal-referencial, señalado por Foucault en Las palabras y las cosas como "episteme" arqueológica de los siglos XVI y XVII) ${ }^{6}$ sino también en su teatralidad literaria $^{7}, y$, aun, en su teatralidad lúdica

\footnotetext{
s7bid., p. 10.

${ }^{6}$ Foucault, Palabras, 1996.

${ }^{7}$ Said, Orientalism, 1979, p. 55.
} 
artística y radical, constitutiva del lenguaje y del conocimiento mismo. ${ }^{8}$ Una "poética del otro" (analogada a las fenomenológicas "poéticas" bachelardianas por Said) que, en su raíz práctica, va siempre acompañada por una "dramática del otro" que la intensifica. Recogiendo lo anterior, la metáfora europea del "otro" aparece como un expansionismo teatral lingüísticamente usufructuado, y ocultado por una "gramática" de la transparencia referencial. Contemos ahora, en estas metáforas, nuestra historia.

Edmundo O'Gorman enfatiza cómo la "cuarta parte" del mundo (el continente americano) transformó la cosmología del siglo XV y redujo, con una elocuencia gráfica, las dimensiones europeas relativas. ${ }^{9} \mathrm{El}$ "Novo Mundo" reúne, compensatoriamente, en un único bloque, al "Viejo Mundo". El europeo es ahora el "amo del mundo" al conocerlo por entero; conocerlo en su "globalidad" le permite (y le impele a) plasmar en él su propio mundo a través de sus diversas y civilizadas tecnologías. Aquella desproporción y este poder ponen en marcha y proveen el combustible permanente al motor conquistador-colonizador, que cruza el Atlántico como por un "Nuevo Mediterráneo". La "invención de América" sería, de este modo, una empresa peculiar del expansionismo europeo del siglo XVI en adelante, fundada, para O'Gorman, en el complejo de una conciencia excedida, y en su poderío técnico sobre el espacio, vencedor de las distancias, transportable. Es un expansionismo que se desarrolla a través de una cartografía "deshabitada".

Pero no se trata de una novedad que se agota y consuma en el "descubrimien-

${ }^{8}$ Gadamer, Verdad, 1984, pp. 154-222.

${ }^{9}$ O'Gorman, Invención, 1984. to"-"invención" de América: también sobre África, Europa extenderá más tarde la mirada objetivadora. Mary Louise Pratt muestra cómo la figura escrituraria del "Resto del Mundo" de los escritores y lectores europeos de los siglos XVIII y XIX integra ya a África, América y Asia: "a Eurocentered form of global or, as I call it, 'planetary' consciousness"; 10 "European "planetary consciousness"' "'conciencia "planetaria' europea"). ${ }^{11}$ Se trata, en esta instancia ya avanzada del colonialismo, de una "anticonquista" (anti-conquest), distinguida de la anterior "conquista", abierta y desembozada, y que es denunciada por Pratt en la nueva mirada científica sobre las colonias: una interiorización-sutilización de la dominación, que se esconde en aquella "mirada", tal como lo evidenciara Foucault: "Seeing-man [...] he whose imperial eyes passively look out and posses [...] a European bourgeois subject simultaneously innocent and imperial". ${ }^{12}$

De Colón a los relatos de viajes científicos de los siglos XVIII y XIX continúa la preeminencia del "ver": del "descubrir" al inner eye ("ojo interior-íntimo-recóndito"). ${ }^{13}$ Un "ojo íntimo" para lo oscuro, lo secreto, los interiores (de las cosas y de los continentes colonizados); que tiene una connotación peculiar en el caso de África, sometida a un registro exhaustivo en la época: el "ojo íntimo" en la parte más os-

10 "Una forma eurocentrada de conciencia global, o, como yo la llamo, conciencia 'planetaria'." Pratt, Imperial, 1992, p. 5.

${ }^{11}$ Ibid., p. 9.

12 "Un hombre-que-ve [...] ése, cuyos ojos imperiales pasivamente se asoman y toman posesión [...] un sujeto burgués europeo simultáneamente inocente e imperial," lbid., p. 33.

${ }^{13}$ Ibid., p. 60. 
cura del mundo (en todos los sentidos). Un expansionismo por encima del ocultamiento de los hombres dominados y esclavizados tras la naturaleza superproductiva, y que el mismo estudio de Pratt nos permite llevar aún más atrás del siglo XVIII, y aun del siglo XVI: el "historiador natural", renombrando-clasificando el mundo, es "Adán en el Jardín de Edén" y es el "orden" introducido en el "caos", ${ }^{4}$ vertiente hebrea y vertiente griega de un poder lingüístico sobre una naturaleza sin gente, paradisíaca y explorada. Pero tal vez nos hayamos excedido históricamente respecto de lo que los contactos de Europa con América y África nos posibiliten: las raíces del expansionismo, en términos hebreos y griegos, precederían largamente a la construcción de la "otredad" americana y a la incursión moderna en la "excesiva" naturaleza africana. Si buscamos en la "otredad" hebrea o griega tradiciones en las que la Europa moderna se reconoce constitutivamente, nuestra cartografía y demografía investigativas se desplazan, no sólo hacia atrás en el tiempo, sino a Asia. ${ }^{15}$

${ }^{14}$ Ibid, p. 32.

15 "Europa" ciertamente es una mitificación de los diversos, conflictivos y complejos procesos históricos que la constituyen; de igual modo su reducción a dos "vertientes culturales": "hebrea" y "griega". Lo mismo sucede con "Oriente". Clifford, Predicament, 1988, cap. 11. Pero estos constructos retóricos tampoco pueden ser negados en cuanto ficciones operativas de gran efectividad en la construcción identitaria de las naciones europeas occidentales durante los siglos que siguieron a la caída del imperio romano de Occidente, a las invasiones de los pueblos del norte y a la expansión islámica sobre el Mediterráneo, es decir, a lo largo de la edad media, especialmente a partir de los siglos VIII y IX. La ideología tiene su fuerza específica; su crítica es necesaria para descomponerla en sus elementos heteróclitos silenciados, pero ello no puede
Según Edward Said, ${ }^{16}$ "Oriente" es la fuente y el "otro" constitutivo de Europa: permanente, originario, histórico. El "Orientalismo" es el discurso colonial europeo por excelencia, el más antiguo, arqueológico: nivel profundo del uso explícito del "saber de/sobre Oriente" en la argumentación colonialista moderna. La acumulación libresca-institucional en torno a "Oriente" ha erigido un "promontorio" 17 constituido en "panóptico"18 autorizado sobre la "otredad" (inauguralmente "oriental"), a la vez monumental y estricto, enciclopédico y especializado. Saber dispuesto para controlar a los "otros" y a los propios. "Categoría media" que, entre la novedad y lo conocido, entre la "racionalidad" occidental y los "excesos" y "misterios" orientales, ha sedimentado en la tradición una posibilidad de incorporación y control de todo "otro": cierre de una dialéctica acumulativa sobre una esquematización ya nunca más percibida.

Europa ha construido su "Oriente" para conjurar la disolución en la "desorientación": frente al nomadismo de un "otro" espacial, ha fijado un centro, defensivo y expansivo. Se ha representado "lo oriental" como silencio, mudez, negatividad, lujuria, crueldad, retraso, lentitud. "Oriente", para "Occidente", se ha suspendido entre una caótica materialidad y una pura espiritualidad (nihilismo absoluto): en ambos casos requiriendo un ( $\mathrm{Su}$ : el europeo, recogido en el genio hegeliano) espíritu orde-

llevarnos a desconocer su poder simbólico en la estructuración de la acción social y de las representaciones colectivas, porque, por ser hipercríticos, nos volveríamos ingenuos.

${ }^{16}$ Said, Orientalism, 1979.

${ }^{17}$ Pratt, Imperial, 1992.

${ }^{18}$ Foucault, Vigilar, 1984. 
nador. De aquella oscura dinámica identificatoria, siempre ha salido a flote la "flexible superioridad posicional" (flexible postional superiorita) de Europa. ${ }^{19}$ Una fantasmática persistente, obsesión astuta.

It is Europe that articulates the Orient; this articulation is the prerogative, not of a puppet master, but of a genuine creator, whose life-giving power represents, animates, constitutes the otherwise silent and dangerous space beyond familiar boundaries. ${ }^{20}$

Entre el "otro" opuesto y el "otro" mimético (semejante), Europa pone en escena siempre las diversas figuras de una diametral o (a)simétrica inferioridad. La distribución infinita de los referentes "orientales" y sus disciplinas (en todas las ciencias y las literaturas) supone un deseo, una ansiedad: no tiene tanto que ver con "Oriente" (tal vez mejor, y en todo caso, con los "orientes") como con el mundo eurocentrado, el mundo de los europeos. ${ }^{21}$

Si bien Said se concentra en textos de autores ingleses, franceses y estadunidenses (las tres potencias colonialistas) sobre el Oriente Mediterráneo desde el siglo XVIII al $x x$, partiendo de la expedición napoleónica a Egipto en 1798 (modelo de apropiación científica de "Oriente": "modern Orientalism", "orientalismo moderno”, según él lo llama), nos da, sin embargo, algunas pistas para nuestra búsqueda

${ }^{19}$ Said, Orientalism, 1979 , p. 7.

20 "Es Europa la que articula a Oriente; esta articulación es la prerrogativa, no de un maestro de títeres, sino de un genuino creador, cuyo poder de dar vida representa, anima, constituye el de otro modo silencioso y peligroso espacio más allá de las fronteras familiares." Ibid., p. 57.

${ }^{21}$ lbid., p. 22. arqueológica. "Occidente" se hace una representación de "Oriente" "a su imagen y semejanza": "the Oriental was always like some aspect of the West". ${ }^{22}$ La relación, filológicamente mediada, se establece entre el "antiguo" Oriente y la "moderna" Europa: "Oriente" le indica siempre su origen y la posibilidad permanente de su propio renacimiento, de su regeneración. Pero, más aún, en "Oriente" Europa encuentra -inventa- la posibilidad de pensarse como construcción de un "mundo" a partir del "caos" (raíz griega) y/o de la "nada" (raíz hebrea); y aún más, de crearordenar "mundos" allí donde su "presencia" tenga lugar. "Oriente" es el ámbito de su doble ingeniería: a partir de dónde construye/inaugura su "mundo" y dónde está destinada a construir/expandir su "mundo". Cruzadas y restauraciones repiten incansablemente "the theme of Europe teaching the Orient (and constructing there) the meaning of liberty": "free cities". ${ }^{23}$ Y todavía seguirá siendo así, sin embargo, cuando, al afirmar su rotundo fracaso, afirme simultáneamente su propio origen: "the untuly - un Occidental- nonhistory of the Orient". ${ }^{24}$

Europa hace "nuevos mundos", como Dios ha hecho una vez el Viejo Mundo (eurocéntrico): ${ }^{25}$ la "reconstrucción" del "antiguo" (aunque contemporáneo) Oriente ${ }^{26}$ se dirige en esta perspectiva. Y, así como

22 "Lo oriental era siempre respecto de algún aspecto de Occidente." Ibid., p. 67.

23 "El tema de Europa educando a/enseñando Oriente (y construyendo alli) el significado de la libertad": "ciudades libres". Ibid., p. 172.

24 "La ingobernable no occidental no historia de Oriente." Ibid., p. 151.

${ }^{25}$ Ibid., p. 121.

${ }^{26}$ Ibid., p. 168. 
en la Biblia Dios crea hablando, el discurso y la filología son los medios operativos de este "Orientalismo". Para Renán, fundador de la filología moderna, a mediados del siglo XIX el filólogo es el "creador secular" que saca a la luz de las ciencias humanas el poder ordenador-representador del lenguaje; es el llamado "descubrimiento (desacralizador) del lenguaje (desacralizado)", como señala Foucault. ${ }^{27}$

En nuestro contexto latinoamericano de las elites criollas nacionales europeizantes de fines del siglo XIX y principios del xx, la analogía de Domingo Faustino Sarmiento, en su Facundo, o civilización y barbarie (1845), entre la "barbarie americana" y los "árabes", herencia legada por la convivencia española, representados como detenidos en el siglo XII, se transforma décadas más tarde en el combate cuasimetafísico de la espiritualidad hispana-latina antidemocrática, en el Ariel (1901) de José Enrique Rodó, que se inspira largamente a su vez en la aristocracia filológica de Renán contra la "masa" (en último caso siempre "asiática"), es decir, el "Calibán" estadunidense-anglosajón, perdido y ciego en su pragmatismo instrumental. En ambos casos, si bien valorativamente disímiles, los ideologemas que reúne "lo oriental" son aplicados a lo "otro" (nomadismo, fatalismo, tiranía, atraso, inorganicidad, arbitrariedad, materialidad, mundanidad práctica y comercial; distribuidos en proporciones distintas en cada desplazamiento analógico). En ambos casos, la apuesta europeizante monta la "creación de un mundo" en las apenas "antiguas" colonias.

"Orientalismo" en el que nos hallamos (vía experiencia colonial) europeamente involucrados, y que nos lleva hasta las raí-

${ }^{27}$ Ibid., p. 140. ces griegas y hebreas de la "otredad" europea y de sus figuras del "otro", mostrando, a la vez, la construcción arqueológica de la "alteridad" y la pulsión expansiva, en un mismo movimiento. El poder lingüístico creador-ordenador es un avance sobre la "otredad", fundador y pedagógico: "it was the West that moved upon the East, not vice versa". ${ }^{28}$ Un "otro" espacial puesto bajo la ansiedad de su captura al fondo de la pura contemplación "representativa" y bajo el dominio expansivo de dicha "representación". La representación "reduce" para establecer el "dominio" progresivo: ése es el diseño objetual de la filosofía y de la teología, que encuentra su coronación en la ciencia, todas ellas europeas. Ambos, "dominio" y "reducción", tienen un sentido espacial, cognitivo y político, tal como reflexiona Heidegger en La época de la imagen del mundo. El "otro" tiene, por lo tanto, esta connotación espacial, cognitiva y política. En esta empresa confluyen la tradición hebrea del lenguaje creador de mundos y la tradición griega del kósmos emergiendo del jáos, superioridad logo-política, exclusiva de la lengua y de la cultura "griegas", según la propia apreciación.

Hayden White propone, como metáforas fundacionales del "otro" en estas dos tradiciones europeas constitutivas: en el horizonte hebreo, la distinción propia respecto de los "paganos", según la dramatización de una progresiva "diversificación" física y cultural (podría decirse que la multiplicación babélica de las lenguas y la lejanía -lingüística, geográfica, religiosarespecto de los antecesores y de los lugares de la Revelación otorgan al "otro" el papel

28 "Era Occidente que se movía hacia el Este, no viceversa." Ibid., p. 73. 
secundario del "perdido"); en el horizonte griego, la distinción propia respecto de los "bárbaros", según la dramatización de una marcada "división" moral y metafísica (podría decirse que la argumentación política griega, frente a la tiranía natural de las pasiones en la exterioridad no griega, otorga al "otro" el papel secundario del "acrático"; por exceso o por defecto, en todo caso no virtuoso) ${ }^{29}$ En términos de cultural patterns (expresión tomada de Ruth Benedict: "patrones culturales") y ante el vínculo con esos "otros", dirá White: por un lado, tenemos una tradición guilt oriented ("orientada a la culpa"), la hebrea; $y$, por otro lado, tenemos una tradición shame oriented ("orientada a la vergüenza"), la griega. La "unificación" de cada una con sus respectivos "otros" será motivo de énfasis diversos: de "ansiedad" para la hebrea, de "deseo" para la griega; pero en ambas se trata de cubrir al "otro" con la propia capa, con el propio semen del verbo (semina verbi; "semillas del verbo"); en ambos casos, el lenguaje cumple un papel protagónico. Los "filósofos" griegos (más estrictamente, atenienses) agudizarán esta reducción lógico-lingüística (de un lenguaje reducido a lógos), constituyendo la cara griega del monoteísmo hebreo: el dáimon socrático de Platón, el topos uranos (lugar celestial de las Ideas) de Platón, el Dios metafísico de Aristóteles.

El "otro" y el "sí mismo" imaginados son una carencia mutua constitutiva: como para Platón, en El banquete, la mítica del inquieto Eros, hijo de Poros y Penía, del Recurso y la Necesidad, es sometida a la reflexión filosófica en procura de definiciones esenciales; en la mítica hebrea, la soledad adánica en el Paraíso. En ambos

29 White, Tropics, 1978. casos, un "sí mismo" próximo, masculino, central, hombre piadoso o ciudadano libre; una insatisfacción de ese "sí mismo" en su incompletitud; carencia convertida en abrazo del "otro", en un nuevo poder resentido de conquista y misión. Lo que esa tarea sobre el "otro" no puede aceptar es la incompletitud, porque ha visto como "incompletitud" su propia diferencia: su ser sobrevenido, secundario, alterizado, puesto originariamente en relación, desde-el-otro, que no es cualquier "otro": descle un Otro monoteístico, monológico, monolingüe, único, aplastante, colonizador, que no deja respiro. ${ }^{30} \mathrm{La}$ "diferencia" que viene del Otro, luego disfrazada de "mismidad", de centralidad con iniciativa, se percibe previamente culposa, o indigna, y se desenvuelve por ello en una conciencia reconciliadora, o heroica. La conciencia europea combate la "diferencia" porque la sufre, no la goza: le pesa una única apreciación sobre sí.

${ }^{30}$ Derrida, Monolingüismo, 1997. Sería necesario destacar, en el texto de Derrida, el peso de este único Dios en el monolingüismo del Otro constitutivo, en cuanto experiencia judaica. En la experiencia religiosa popular de nuestros diversos contextos regionales latinoamericanos, el monoteísmo cristiano-católico sobrevenido con la conquista y la colonia nunca ha sido tan totalizante, tal vez por la teología trinitaria en que éste se inscribe y que se desborda en infinidad de santos, tal vez por la compleja conjunción de dioses cristianos y autóctonos en que dicha experiencia se configura y que establece una política de resistencia en el contexto ritual. Véase Grosso, "Suerte", 1994; "Indios", 2001. Esto afecta una hondura constitutiva y abre un nivel de lectura profunda, más allá del folclotismo, del exotismo antropológico y del discurso pastoral o teológico. La deconstrucción del monoteísmo en nuestras ciencias sociales y el estudio del fenómeno religioso en nuestra interculturalidad poscolonial es una tarea pendiente. 
La deconstrucción, que abre el territorio proscripto de la "diferencia", más que dejar en claro los múltiples procesos de la "mismidad", se demora en la primera "diferencia", generadora de la propia impotencia, a la vez como margen y anuncio de su perversión: un gesto de don y acogida que se descompone en fuerzas de sentido en este nivel primario, cumpliendo y transformando la relación. ${ }^{31}$ Una "rebelión triunfante de esclavos" 32 sólo puede ser revertida por el triunfo de la rebelión de los esclavizados: ésta es la intuición histórica del pensamiento crítico poshegeliano, que crece de Marx a Gramsci; aunque Derrida piensa en márgenes y no en "revolución". ¿Qué tanto de estos tropos totalizantes tiene que ver con el Dios monoteísta?

\section{El Héroe en el Paraíso. \\ LA CONSTRUCCIÓN DE LA HEGEMONÍA COLONIAL EUROPEA Y ESPAÑOLA}

En los últimos 25 años, la vuelta a las narrativas de conquista y colonización, con nuevos ojos y con oídos alertas, en procura de los senderos menos explícitos de la dominación, de las seducciones y de las resistencias, ha producido en las ciencias sociales y humanas varios ensayos interpretativos y nuevos relatos de los procesos históricos americanos.

Tzvetan Todorov, en La conquista de América. La cuestión del Otro, ${ }^{33}$ aunque esquemáticamente, propone comprender aquellos primeros encuentros como un "hecho comunicativo". Sin embargo, se

${ }^{31}$. Derrida, Monolingüismo, 1997.

${ }^{32}$ Nietzsche, Genealogía, 1986.

${ }^{33}$ Todorov, Conquista, 1985. ahorra demasiado pronto la demora necesaria en el análisis de aquel mundo de equívocos, de aquellas paradójicas mediaciones interculturales, y (en)cierra lo mexicano (Moctezuma y los grupos de poder de su entorno) en un sistema de comunicación que dirige sus signos al "mundo", esa gran área nebulosa de los dioses, de lo "sobrenatural". A ello contrapone la nueva modalidad cultural-epocal, representada en Cortés, como avanzada de los europeos modernos, que habría secularizado los signos frente a un "otro" de carne y hueso, entendible y manipulable. De este modo, Todorov no hace más que proyectar (una vez más en aquella vieja historia) los prejuicios ilustrados.

Inga Clendinnen, a pesar de sus elogios a la obra de Todorov, y ahondando igual que aquél en la "conquista de México" en cuanto "hecho de comunicación", muestra más bien el hiato incomunicativo o, mejor, las sucesivas "comunicaciones fallidas" entre mexicanos y españoles. ${ }^{34}$ Aun cuando la situación de guerra, según la autora, sería la más propicia para un auténtico intercambio de mensajes en los primeros encuentros: "in deadly combat the veils of 'culture' are ripped away, and natural man confronts himself". ${ }^{35}$ Sin embargo, dicha guerra termina mostrando la mutua "otredad" en los términos más radicales. La guerra, como el juego de cricket (analogía que establece la autora),

(obliges) a mutual "transmission of culture" of the shotgun variety [...] it promises to expose how one's own and other ways of acting

${ }^{34}$ Clendinnen, "Fierce", 1991.

35 "En el combate a muerte, los velos de la "cultura' son rasgados y el hombre natural se confronta consigo mismo." Ibid., p. 77. 
and meaning are understood and responded to in crisis conditions, and what lessons about the other and abour oneself can be learned in that ultimate, involuntary, and most consequential communication. ${ }^{36}$

Una lectura oblicua de las narrativas de la "segunda fase" de la conquista de México (desde la Noche Triste hasta la caída de Tenochtitlán): los textos de Cortés (sus Cartas), de Bernal Díaz del Castillo (Historia verdadera de la conquista de la Nueva España) y de Bernardino de Sahagún (Historia general de las cosas de Nueva Espa$\tilde{n} a$, Códice Florentino), como asimismo las fuentes pictográficas nativas, le permiten ver a la autora "los contornos generales de la conducta de los nativos en el campo de batalla". ${ }^{37}$ Las notas principales de dicha conducta son el lugar central del campo de batalla en la imaginación de las sociedades guerreras del México central; el carácter sagrado de los enfrentamientos; la igualdad de fuerzas requerida en los oponentes; la simbolización de la conquista en el incendio del templo de los vencidos y en la captura de la imagen de su dios tutelar, que era trasladada a la "casa del dios cautivo" en Tenochtitlán; un corto periodo de saqueo y destrucción antes de la imposición del tributo al vencido; el carácter singular del guerrero: su prepa-

36 "La guerra, como el juego de cricket, obliga a una mutua 'transmisión de cultura' sobre la variedad de tiros [...] ella [la guerra] promete mostrar cómo, tanto el propio modo de actuar y de significar, como el de los otros, son entendidos y respondidos en condiciones críticas y qué lecciones sobre el otro y sobre sí mismo pueden ser aprendidas en aquella comunicación definitoria, involuntaria y más cargada de consecuencias." Ibid., p. 77.

37 lbid., p. 78. ración por medio de cantos, la pintura y atavío de su cuerpo, el carácter particular de la lucha, cuerpo a cuerpo, uno a uno, y la potenciación dramática del encuentro; $y$, finalmente, la captura de algunos prisioneros significativos del bando enemigo. ${ }^{38}$ Gracias al relieve y la corporización dada a la lectura de las entrelíneas de aquellas fuentes, Clendinnen puede marcar las distancias suficientes en aquel "encuentro" para concluir en una "comunicación fallida" (miscommunication) entre españoles y mexicanos, durante y al final de las batallas: "the identifiable confusions [...] ran both ways". ${ }^{39}$ Los españoles no entendían por qué (dignamente) los sitiados no se rendían; mientras éstos, con sus guerreros individuales, entendían que los españoles, atacando en masa y refugiados (vergonzosamente) tras el cañón, eran el signo, no de una derrota, sino de la destrucción total, definitiva e inevitable de la era del Imperio Azteca, la humillación final de su derrumbe. La arremetida devastadora de los tlaxcaltecas, antes sometidos al dominio azteca y, al momento de la conquista, aliados de los españoles, su "ferocidad e innatural crueldad" contra los sitiados y su ciudad (tal como lo percibe y expresa Cortés en su relato), y que no tenía precedentes para las expectativas bélicas de los españoles, enrostra a éstos con la más absoluta "otredad". Cortés queda perplejo ante el fracaso, en definitiva, de sus previsiones estratégicas (aunque haya triunfado militarmente): la "innatural" indiferencia ante el sufrimiento y frente a la muerte distancian a los nativos (tanto tlaxcaltecas cuanto aztecas) de todo sentido "español" de hu-

38 Ibid., pp. 78-79.
39 "Las claras confusiones [...] marchan en dos caminos divergentes." Ibid., p. 71. 
manidad: "a terryfing, terminal demonstration of "otherness"'.40

Esto conduce a Clendinnen a una conclusión diferente a la de la pericia cortesiana sobre los mexicanos, exaltada por Todorov: "its practical and cognitive unmanageability". ${ }^{41} \mathrm{La}$ "conquista" termina en la incomunicación, una comunicación frustrada para la dominación. La autora enfatiza la incontrolabilidad en la pretendidamente exitosa y total "conquista del otro" según Todorov: a los españoles no les alcanza, en su dominio de los signos, el (tan declamado) decisivo "paso evolutivo" hacia la escritura, tomada como índice de desarrollo de las estructuras mentales, y que habría liberado la inteligencia permitiéndole una gran flexibilidad en la construcción de estrategias y una compleja capacidad semiótica, todo lo cual habría determinado el triunfo de Cortés y sus hombres para Todorov. ${ }^{42}$

La exterioridad de la "alteridad" y su reducción al "orden topográfico del lenguaje", a la "espacialidad escrituraria", es el medium en el que se mueve el estudio de Michel de Certeau en torno al "discurso del otro" ${ }^{43}$ Hay una "circularidad" entre la "producción del otro" y la "producción del texto" que lo inscribe; ${ }^{44}$ un "texto", precario pero manipulable, construido ante la exterioridad inaccesible (bors-texte; "fuera del texto"), (re)espacializada en su "imagen" escrita. Este "texto mediador" (interspace; "espacio intermedio"), según el

40 "Una aterradora y definitiva demostración de 'otredad'." Ibid., p. 94.

41 "La imposibilidad práctica y cognitiva de gerenciabilidad sobre los indígenas." 1bid., p. 94.

${ }^{42}$ Ibid., p. 66.

${ }^{43}$ De Certeau, Écriture, 1975; Heterologies, 1986.

${ }^{44}$ De Certeau, Heterologies, 1986, p. 69. autor, es producido en el momento singular de la transición de una "exégesis teológica" a una "exégesis del otro (salvaje)", simultánea con el descubrimiento de América y sus vicisitudes posteriores: una pulsión infinita de escritura animada por aquellos extraños cuerpos y voces inapresables, y por ello mismo metaforizante: lleva al decir a sus límites, deriva sentido en el sinsentido. La "alteridad de la oralidad", oída por el sujeto narrador del relato de viaje, Jean de Léry, en las costas de Brasil, L'Histoire d'un Voyage (1578), es comprendida por De Certeau como différence de l'oralité ("diferencia de la oralidad"), rumorosa por detrás de la opération scripturaire ("operación escrituraria"; que también es una "operación traductora"). La "etnología se esboza así como ciencia de la fábula (las cosas que se cuentan sin dar razón exhaustiva de sî), trascendencia/interferida/tachada por aquellas voces de los otros, su murmullo y rumor inconquistables, que a su vez presionan hacia la tarea imposible/ incesante de escribir. ${ }^{45}$

Por otro lado, en territorio europeo, la alteridad ritual es incluida/invertida en la tradición grecoeuropea del "salvaje" en el escéptico y paradójico De Cannibales de Michel de Montaigne, al ser "arqueológicamente" remitida por la cita del libro IV de las Historias de Heródoto: del modo más general y abarcativo, hiperbólico, "lo que la más refinada tradición dorada del Mediterráneo tiene para ofrecer es usado por de Montaigne para forjar un halo sobre los caníbales"; antiguos héroes guerreros y mujeres virtuosas alteran la valoración cristiana moderna del "canibalismo" y de la "poligamia". Respecto al "canibalismo", el poder del cuerpo arrojado a la

$$
{ }^{45} \text { De Certeau, Écriture, 1975, cap. } 5 .
$$


muerte es lo que en verdad se incorpora en la ingestión; respecto a la "poligamia" (poligenia), en verdad se trata de mujeres virtuosas que se deben en cuerpo y alma a su único marido. Pero sólo se realiza la inversión escéptica recurriendo (otra vez, y de otro modo, a las propias fuentes europeas. ${ }^{46}$ Michel de Certeau marca, en los textos anteriores, la mediación del propio mundo europeo en la construcción del "otro" y la radical extrañeza incomunicada en que quedan la oralidad y la ritualidad nativas.

Patricia Seed señala un "paradiscursivo ceremonial" en el establecimiento de la autoridad y la dominación coloniales en el "Nuevo Mundo". ${ }^{77}$ Sin embargo, dicho "paradiscursivo" ha estado siempre ligado a la escritura y sus prácticas:

aun cuando la conquista del Nuevo Mundo fue a menudo realizada por medios militares o por ocupación, su autoridad -es decir, el derecho de gobernar-fue establecido por medio del lenguaje y de la ceremonia". ${ }^{48}$

Seed establece una diferenciación en los modos europeos de instaurar y justificar su autoridad: español, inglés y portugués. De ellos, el que de un modo peculiar destaca la vinculación entre poder y escritura, aun en el momento mismo de la toma de posesión de los nuevos dominios, es el español. "These two key elements -the renaming of landmass and the ceremonial declarations- instituted Spanish colonial authority through an act of speaking, a dramatic enactement of

\footnotetext{
${ }^{46}$ De Certeau, Heterologies, 1986.

${ }^{47}$ Seed, "Taking", 1992.

${ }^{48}$ Ibid., p. 184.
}

belief in the power of words". ${ }^{49}$ Tal vez esto se deba, señala Seed, al énfasis español en una dominación establecida en primer lugar sobre la gente. Una oscura necesidad de un "otro" que podría tener una doble vertiente: una propiamente española, otra propiamente europea, como veremos en seguida; pero a la autora le interesa aquí marcar la diferenciación entre españoles, ingleses y portugueses:

What the (Spanish) act of reading accomplishes, in contradistinction to English architectural symbolism or Portuguese stone posts and flag painting, is the establishment of authority over people [...] over persons rather than over land (English) or commerce (Portuguese)..$^{50}$

Sin descuidar estos énfasis, sin embargo, la conquista española de la "gente" también sirve a intereses genéricamente europeos.

La vertiente "española" de la necesidad (española) de un "otro" podría estar ligada a la Reconquista y a la cuestión concomitante del "honor", tal como lo deja apenas planteado Bartolomé Benassar en su obra

49 "Estos dos elementos clave -la redenominación de las tierras y las declaraciones ceremoniales (se refiere a la toma de posesión ante escribano, que más tarde consistirá en la lectura del "Requerimiento", y al acta de fundación de las primeras ciudades- instituían la autoridad colonial española a través de un acto de habla, un dramático decreto de creencia en el poder de las palabras." lbid., p. 199.

so "Lo que la acción española de leer realiza, a diferencia del simbolismo arquitectural inglés o de los pilares de piedra y las banderas pintadas de los portugueses, es el establecimiento de la autoridad sobre la gente $[. .$.$] sobre personas antes que sobre las tierras$ -como los ingleses- o sobre el comercio, como los portugueses." Ibid., p. 205. 
Los españoles. La mala conciencia en el desplazamiento de una cultura "superior" árabe-mediterránea hipersensibilizó a los restauradores del catolicismo, encaminándolos hacia la tortuosa búsqueda de un reconocimiento social y político requerido de los "superiores" (el Papa y la Cristiandad) y de los "inferiores" (árabes-ibéricos vencidos), respecto de su obra, recristianizadora y relatinizadora. La conquista de América acrecentó la posibilidad de "ganar honor" ante una cultura "a ojos vista" (ojos europeos, ciertamente) "inferior", apreciación garantizada por su diferencia extra-europeo-mediterránea y extrabiblica.

Esto marca una diferencia contextual "nacional" en la construcción de la alteridad, respecto de la ruptura anglicana y la hegemonía nacional inglesa en Gran Bretaña, y respecto del imperio comercial católico portugués, en plena expansión (Inglaterra y Portugal, las otras dos naciones europeas colonialistas a las que nos referimos con Patricia Seed más arriba): una mala conciencia española, ansiosa de bendiciones y agradecimientos, puso en vilo las antiguas figuras del "pagano" y del "bárbaro". Por otro lado, la vertiente "europea" de la necesidad (española) de un "otro" está ligada al argumento central que vengo desarrollando en este artículo, y por eso se explicitará con mayor claridad más adelante. En todo caso, concluyendo con el trabajo de Seed, "Spanish authority was textual imperialism par excellence -the reading of a Western text to uncomprehending natives." 51

51 "La autoridad española era un imperialismo textual por excelencia (en el que la autora incluye las escenografías ceremoniales) -la lectura de un texto occidental a nativos perplejos e ininteligibles." Ibid., p. 209 .
Esta misma autora, en otro trabajo, ${ }^{52}$ desplaza el énfasis puesto en la dominación escrituraria del "otro": del ejercicio de las prácticas ligadas al escrito, hacia las operaciones intratextuales mismas. El texto colonial es, por un lado, la expansión de la soberanía europea sobre las voces y gestos "bárbaros" del indígena; pero, cuando el propio indígena escribe, es otra la "topografía" que diseña en relación con la oralidad y las heteroescrituras de su propia tradición. Tal vez el caso más relevante sea el de Felipe Guaman Poma de Ayala en su El primer nueva corónica y buen gobierno (1615). Seed toma como punto focal de interés el relato del encuentro de Pizarro con Atahualpa en Cajamarca, en sus cuatro versiones escritas: la de Francisco de Jerez (Verdadera relación de la conquista del Perú, 1534), la del Inca Garcilaso de la Vega (Comentarios reales de los incas, 1617), la de Titu Cusi Yupanqui (Relación de la conquista del Perú, 1570) y la de Felipe Guaman Poma. Cada una de ellas "comienza" a contar la historia a partir de un momento diferente:

En el registro de Jerez, la narrativa comienza con la estrategia militar; en el de Titu Cusi, con la temprana provocación de derramar la chicha sagrada; en el de Guaman Poma, con la dignidad y majestad del propio Inca; y en el de Garcilaso, con la deferencia de Atahualpa hacia el "obviamente superior" orden social español. ${ }^{53}$

Diversos "comienzos" hacen distintas "historias". La autora relativiza de este modo la "historia oficial" de Francisco de Jerez, derivando, de un interés positivista

$\$ 2$ Seed, "Failing", 1991.

33 lbid, p. 30. 
sobre lo que "en realidad" ocurrió (el incidente paradigmático y estereotipado del diálogo del padre Valverde y de Atahualpa en torno al "libro", la Biblia, y el detonante gesto de desprecio por parte del Inca al olerla y arrojarla al suelo), hacia las operaciones constructivas de la "alteridad" en las narrativas coloniales, vinculadas a la escritura de la "historia". El relato de de Jerez pone de manifiesto, en la corriente de la tradición a la que pertenece, "a historical continuity in Western expectations of the conduct of non-European peoples (at writing)" ${ }^{54} \mathrm{El}$ paradójico "diálogo" de las narrativas coloniales con el "otro" se cumple dentro del acuerdo, o del conflicto, (pero siempre al interior) de las propias tradiciones europeas. Las técnicas textuales del "discurso colonial" son ejemplificadas por Peter Hulme ${ }^{55}$ a través de diversas configuraciones de aquella intertextualidad "monológica". La discusión interior que sucede en el texto acerca del "otro" acalla y se alza imperativamente sobre las confusas voces y oscuras señales indígenas. El "discurso colonial", linguistically-based practices ("prácticas basadas en el lenguaje") ${ }^{56}$ constituye, de este modo, una esfera textual de poder, potenciadora de las propias tradiciones:

The radical dualism of the European response to the native Caribbean -fierce cannibal and noble savage- has such obvious continuities with the classical Mediterranean paradigm that it is tempting to see the whole intrincate web of colonial discourse as weav-

54 "Una continuidad histórica en las expectativas de Occidente sobre la conducta de la gente no europeas ante la escritura." Ibid., p. 19.

55 Hulme, Colonial, 1986.

${ }^{56}$ Ibid., p. 2. ing itself in its own separate space entirely unaffected by any observation of or interchange with native Caribbean cultures. ${ }^{57}$

"Intertextualidad" (expresión tomada de Mijail Bajtin) colonial, que pone así de relieve "a discourse' conflict internal to that European monologue itself [...] into a singular discourse a rethorical plurality or heteroglossia". ${ }^{58}$

En torno al tema (y al ideologema) de los "canibales" (Cannibals), Hulme deconstruye las diversas configuraciones en pugna en la intertextualidad del "discurso colonial". En esta lectura crítica, devela:

1. Una "transformación discursiva" 59 en el Diario de viajes de Cristóbal Colón, vinculando el "discurso oriental" (en la tradición de Marco Polo, y según la articulación de los intereses genoveses) y "el discurso herodotiano" (en la tradición de Heródoto, y según la articulación de los intereses expansionistas castellanos). En el discurso colombino de los "caníbales" (o "caribes"), este término se refiere: o bien (en un principio) a los "soldados del Gran Can" ("discurso oriental"), o bien (luego, a medida que la dirección sudoeste se torna en sudeste, siguiendo la costa Cuba-San-

57 "El dualismo radical de la respuesta europea ante los nativos caribes - canibal feroz y buen salvajetiene tan obvias continuidades con el paradigma mediterráneo clásico, que invita a ver la completa telaraña intrincada del discurso colonial como tejiéndose ella misma en su propio espacio separado, totalmente desafectado de cualquier observación sobre, o de cualquier intercambio con, las culturas nativas caribeñas." Ibid, p. 47

58 "Un conflicto del discurso, interior al monólogo europeo mismo [...] dentro de un discurso singular, una pluralidad retórica, o heteroglosia." Ibid., p. 20.

59 Ibid., p. 39. 
to Domingo) a los salvajes "antropófagos" ("discurso herodotiano"). Un "discurso de civilización oriental" y un "discurso de salvajería", ${ }^{\circ 0}$ también mentados por la metonimia "oro oriental"-"oro salvaje" ${ }^{61}$

2. Una intertextualidad oscurecida bajo la ampulosa retórica de autoridad en la definición de "caníbales" (no "cannibals") del Oxford Englisb Dictionary de 1796, y que dice en dicha entrada: "who are recorded to have been anthropophagi" ${ }^{62} \mathrm{Se}$ ocultan los pliegues de una historia diferente en la "interna opacidad del enunciado": una "transcripción (el Dictionary) de un resumen (la Historia de Indias de Bartolomé de las Casas) de una copia (depositada en el Monasterio de San Pablo en Sevilla) de un original perdido (el Diario de viajes de Colón)" ${ }^{63}$

3. Una intertextualidad en juego dramático en La tempestad de William Shakespeare: "el discurso mediterráneo" (en favor de Próspero) y "el discurso atlántico" (anti-Próspero), simultáneos en la estructura de la obra, y que la crítica literaria ha puesto siempre de relieve.

4. Una intertextualidad en escala analógica en el "relato de Pocahontas", que proyecta en la sombra sus dimensiones (monológicas) más abarcativas. "Narrativas en miniatura" (segmentos comparativos que amarran a John Smith con Odiseo), que sirven para envolver todo el relato en una estructura narrativa más amplia, en la que Polifemo (cannibal) se proyecta sobre Powhatan (jefe de los algonquinos); "los topoi familiares mediterráneos de la literatura

${ }^{60}$ Ibid., p. 21.

${ }^{61}$ lbid., p. 33.

62 "Quienes son recordados por haber sido antropófagos." Ibid., p. 16.

${ }^{63}$ Ibid., p. 17. clásica son usados para enganchar y absorber la novedad de la salvajería caribe (y algonquina)". ${ }^{64}$

5. Una intertextualidad de dos términos yuxtapuestos, con sus respectivas narrativas, en el curso del relato en primera persona de Robinson Crusoe de Daniel Defoe, y que, en una arqueología discursiva, conectan con el tropos básico del discurso colonial europeo: la hospitalidad requerida de "bárbaros" y "paganos", que se muestran entonces como "buenos salvajes" o "feroces caníbales". Se hace la distinción entre "guatiao" (relación colonial europeoindígena construída sobre el intercambio de nombres y el compromiso mutuo: Viernes es "guatiao") y "cannibal" (los raptores de Viernes y la tribu de éste) indicando (y sellando) ambas reacciones contrapuestas. 65

6. Un "subtexto" clásico por debajo del "relato de Inkle y Yarico" en las Bahamas: Dido y Eneas, de la Eneida de Virgilio, al ser citados analógicamente, funcionan como "un subtexto relacionado con el gran tema colonial de la hospitalidad", 66 "el subtexto de los tempranos intercambios coloniales vinculados con la barbarie". ${ }^{7}$ La tormenta, el naufragio, la despiadada recepción de los marinos por parte de los habitantes de la costa, y la elección de Eneas-Inkle por Dido-Yarico, ponen al texto bajo el halo de la tradición, negándole todo carácter inédito a la situación y haciendo de los indígenas inhospitalarios unos "bárbaros".

Finalmente, como cierre monológico ante la exterioridad del "otro", Hulme

\footnotetext{
${ }^{64}$ Ibid., p. 155.

${ }^{65}$ Ibid, p. 209.

${ }^{66}$ Ibid., p. 249.

${ }^{67}$ Ibid., p. 251.
} 
muestra también, en varias oportunidades, navegando en aquella intertextualidad, la diferenciación "en bloque" de la escritura colonial frente a, y por encima de, la germinalidad nativa de sentidos. En el caso de La tempestad de Shakespeare, esto se evidencia en la contraposición de la "narrativa de Próspero" con la potencial "historia propia de Calibán". ${ }^{68}$ En el caso del "relato de Pocahontas" (en sus diversas fuentes y versiones), se impone la réplica prepotente de un discurso de privilegios sociopolíticos (Pocahontas convertida en princess) a prácticas y palabras incomprendidas emitidas dentro del contexto algonquino de "reciprocidad": desde las lógicas y los intereses nativos al gonquinos, "los ingleses eran demasiado peligrosos para ser alejados: una alianza con ellos debía ser establecida, quizás con vistas a absorberlos en la confederación"; 69 y los reproches de Pocahontas a John Smith, en Inglaterra, años después, sólo serían comprensibles al ser remitidos a aquellas prácticas indígenas. ${ }^{70}$

Anthony Pagden también señala el recurso a loci communes de la tradición europeo-mediterránea en el "discurso colonial" español, que operan al modo de "subtextos" en la construcción de la "alteridad". ${ }^{71}$ "Ellos (los observadores europeos) sólo podían volver algo familiar $y$, por ello, inteligible en los términos que una antropología lo autoriza, precisamente por el hecho de que sus fuentes regresaran a los griegos". ${ }^{72}$ Fue así que la teoría aristotélico-escolástica de la esclavitud y de la barbarie fue reformulada en la medida de las nece-

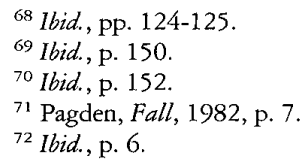

sidades para someter a los indígenas, potenciando a la vez (en proporción inversa) los ideales propios. América, en el siglo XVI, fue vista como "una extensión, en un nuevo espacio geográfico, con las dimensiones familiares y fantásticas del mundo atlántico"; "lo nuevo podía ser siempre satisfactoriamente descrito por medio de alguna analogía simple y directa con lo viejo". ${ }^{73}$ "The very strange strangers", ${ }^{74}$ "(they) had, before being discovered by the Spaniards, existed only in the 'imaginary spaces' of the European mind". ${ }^{75}$

La autopotenciación de Europa ante América y la cuestión española del "honor", de la que hablamos más arriba, encuentran, en la evitada declaración de la "esclavitud natural" de los indios y en la inclinación más bien por su inerme "infancia", una poderosa cualificación del ámbito del autorreconocimiento: Europa inventa su propia misión mundial.

Alcida Rita Ramos bautiza con una nueva expresión la síntesis del europeo colonizador en América, en el entramado del "discurso edénico" ("The brownskinned sweet version of Adam and Eva before the fall") ${ }^{76} \mathrm{y}$ del "discurso civilizador" ("savagery, backwardness, paganism, brutality") ${ }^{77}$ denominándola "the hero in Paradise". ${ }^{78}$ Desde la primera conquista y durante la colonia (y aún hasta sus herederos criollos en las repúblicas actuales), el

${ }^{73}$ Ibid., p. 11.

74 "Los muy extraños extranjeros." Ibid., p. 17.

75 "Antes de ser descubiertos por los españoles, habían existido sólo en los 'espacios imaginarios' de la mente europea." lbid., p. 39.

76 "La dulce versión cobriza de Adán y Eva antes de la caída." Ramos, "Eden", 1994, p. 6.

77 "Salvajería, atraso, paganismo, brutalidad". Ibid.

78 "El héroe en el Paraíso". Ibid. 
europeo se autocomprende y autorrepresenta en América como héroe civilizador en el Paraíso.

Pero, ¿es necesario un héroe en el Paraíso? ¿Qué Paraíso puede requerir o crear las condiciones de la heroicidad? ¿Hasta qué punto dicho héroe ha arriesgado la vida? ¿Cuándo el Paraíso se le ha presentado culturalmente tan ajeno y tan interior a la vez? ¿Cuánta disciplina culposa y sentimiento de indignidad, cuánta ansiedad y deseo, es decir, cuánta tecnología cristiana del yo, conduce hacia una heroicidad en el Paraíso? El europeo es el "héroe en el Paraíso" porque en América y frente a su gente resiste las sensualidades; de pedagogo a mártir, conquista al bárbaro, civiliza al salvaje y evangeliza al pagano; combina la "firmeza de carácter" y la "maleabilidad psicológica" necesarias para colonizar las nuevas tierras. ${ }^{79}$ En una proyección de sí mismo sobre el "indio", transforma a éste en el modelo moral incontaminado para Europa, donde la obra de la civilización preluce cuando está por (re)hacerse. Más tarde, en el siglo XIX, el "indio" europeizado será ejemplar de los más puros valores para las naciones imaginadas como mestizas; y actualmente, en la era de la conciencia ecológica planetaria, el "indio" es ejemplar por su naturalismo puritano según la percepción de quienes son capaces de emerger con heroísmo de un mundo éticamente resquebrajado de antihéroes. En nuestra anquilosada identidad colonial, habitamos aún europeamente estas tierras: el "indio" purificado de su "barbarie" es la viva imagen del origen de la historia, la génesis inmaculada de la "civilización". Imagen que cubre, con distintas configuraciones, los últimos siglos: "esta trayecto-

${ }^{79}$ Ibid., p. 7. ria del discurso edénico, que va del Paraíso encontrado al Paraíso perdido". ${ }^{80}$

La expresión "el héroe en el Paraíso" ofrece una clave hermenéutica que ilumina una zona oscura del "discurso colonial". El "héroe" es, en todo caso, el "civilizado", que refracta, en su mirada sobre el Paraíso, imágenes que van desde la bondad natural hasta la salvajería infantil: bondades que tienen como contenido su propia proyección positiva idealizada; aberraciones y brutalidades que tienen como contenido su propia proyección negativa demonizada. Sin duda, la conquista de México muestra este doble rostro en su narrativa: por un lado, el esplendor de la ciudad azteca, y por otro, la "fiereza e innatural crueldad" de su defensa y destrucción por los nativos, fueran enemigos o aliados.

El "héroe" halla el medio propio de sus aventuras en las narrativas en que se inscribe. ${ }^{81}$ Su espacio es la mediación textual: cruza el "Mar Tenebroso" hasta el "Paraíso", y lo recorre en su épica entre lo familiar y lo extraño, lo conocido y lo desconocido. En el texto halla su punto de partida, sus más largas incursiones en territorios remotos, y su regreso triunfante. Ya sea "viaje", "conquista", "misión evangelizadora" o "empresa civilizadora", siempre es un texto el que narra y dimensiona los riesgos abismales: las escarpadas y contrastantes alturas, las oscuras y tortuosas profundidades. Aún la inversión escéptica de Montaigne es una mirada oblicua, que recorre de modo alternativo (al institucionalizado) la propia tradición en un "ensayo" migrante. Pero, en realidad, da la sensación de que el tal "héroe" nunca pisara tierra extraña, como si nunca hubiera par-

\footnotetext{
${ }^{80} \mathrm{lbid}$., p. 12.

${ }^{81}$ Sinnott, "Sabiduría", 1984.
} 
tido: el "otro" a rescatar siempre le queda demasiado lejos, como si en sí mismo fuera insignificante y sólo la propia traducción heroica lo engrandeciera; traducción que es incorporación al mundo propio de significación. Del "héroe" al "mártir" sólo media la idealización del riesgo, la agudización salvífica, el triunfo moral justificatorio de la propia acción expansiva y la epifanía incendiaria del Dios monoteísta.

Las armas de este "héroe"son un tramado de tradiciones en conflicto: en la prueba competitiva de sus múltiples "espadas" y al fragor creciente de la batalla interior que lo inviste, se le transfigura el nuevo oponente en algún antiguo y poderoso enemigo, vencido pero nunca definitivamente derrotado; su empresa y su psicología son quijotescas, revive la literatura de su tradición rodeado de fantasmas que lo elevan a una gloria central, compulsivamente deseada y diferida, imposible; su campo de batalla es un gran monólogo con varios frentes de disputa internos. ¿Será que el mentado héroe corre el riesgo fuera de sí mismo, o más bien su real riesgo amenaza en su propia constitución? Luchando consigo mismo, derrota al mundo, pero a costa de volver al mundo una cámara de espejos de antiguas ilusiones resucitadas.

El "héroe en el Paraíso" es la imagen proyectada del "héroe" fuera de/desde su propio Infierno. Infierno propio que se vuelve el arma y la justificación para que el Paraíso sea objeto de conquista; tal vez simplemente por la pura e ingenua indefensión edénica, frente a un mundo cercado de peligros que el propio "héroe" reconoce y porta consigo donde va. El "civilizado" parece más preparado para proteger la separación: sus murallas han sido construidas de adentro hacia afuera; su paranoia potenciadora de los peligros se ex- tiende como misión sobre lo ancho del mundo. En el fondo, el héroe monológico parece no haber abandonado nunca el centro amurallado: toma posesión de las nuevas tierras y de la nueva gente con los mismos medios narrativos y escriturarios en los que se desenvuelve su existencia; cuenta la "historia" colocando el "comienzo" bajo sus propios pies; en realidad, en las "historias" cuenta su propia historia; no hace más que escuchar sus voces interiores, la discusión infernal que lo mantiene a salvo de una exterioridad paradisíaca, insignificante en su relajación, idiotizada en su saturación. Sus juegos de lenguaje son resortes que lo impulsan más allá: se oye aquí, muy por debajo, el murmullo secreto de los ideologemas tardíos del "progreso", de la "modernización", del "desarrollo".

Esta "heroicidad" es una cuestión de distancias: la distancia "monológica" le permite establecer sus propias medidas. La tensión que lo habita anima su ansiedad planetaria, su pulsión de hegemonía. La "ciudad" (civitas) es el reino de las medidas; el "héroe" construye ciudades en el Paraíso, es un "héroe civilizador". Según la tradición aristotélica, la ciudad es el lugar del aprendizaje y de la práctica de la virtud. Pagden destaca el papel de Francisco de Vitoria en su actividad académica vinculada al Consejo del rey: ${ }^{82}$ su evaluación sobre las poblaciones indígenas da un relieve crucial a la "ciudad"; ésta es reconocible por la siembra de distancias: entre los distintos estados y castas sociales, entre los mesurados interactuantes en la palabra y la escucha, entre los ámbitos de lo sagrado y de lo profano, entre las familias monogámicamente instituídas. En los

${ }^{82}$ Pagden, Fall, 1982. 
protocolos de la hospitalidad, que era considerada el régimen de interacción adecuado para la relación entre miembros de diferentes ciudades, el extranjero (que en este sentido era no extraño), haciendo ostentación de su respeto de las distancias "civiles" (dentro de su propio grupo y ante los ojos vigilantes de sus anfitriones), distinguía su presencia de una siempre temida invasión, o amenaza de corrupción, y se hacía merecedor, de ese modo, de una recepción amistosa. ${ }^{83}$ Las suertes corridas por los europeos entre los "indios" se transformaron en un gran tema de los encuentros coloniales para la discusión y justificación de las políticas consecuentemente establecidas. ${ }^{84} \mathrm{El}$ maltrato de los recién llegados, con el que se violaba las leyes ("universales") de la hospitalidad, era un signo claro de "pueblos bárbaros" para el acendrado sentido común europeo. ${ }^{85} \mathrm{De}$ hecho, en la argumentación de Francisco de Vitoria era el único motivo racional que tornaba la toma violenta de las nuevas tierras en legítima defensa propia (!) para garantizar el libre acceso de los "hombres de ciudad" a todas las vías y a todos los sitios del mundo. ${ }^{86}$

La empresa heroica se reducía a la extensión e implantación de las propias medidas en el mundo. Ello era lo digno de recordar, y, por lo tanto, el punto de partida para contar la "historia" (que siempre era, de algún modo, desde esta nueva determinación narrativa, otra vez la propia). "'Civility' -European civility- can only guarantee the stability of its own fundations by denying the substantiality of other

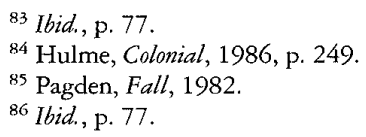

worlds, other words, other narratives." 87 ¿Cuál es entonces la aventura en la exterioridad que el tal "héroe" lleva a cabo con éxito? ¿Cuál su audacia, cuál su astucia? El "héroe colonial" parece tener asegurada de antemano su "inédita" (pero siempre recitada) habilidad para escapar de situaciones difíciles; sin embargo, tal vez por esta (tramposa) "libertad" y "flexibilidad", él puede sostener a cada paso "the image of the everresourcefull hero" ${ }^{88}$ En lo cual resulta evidente que no basta la semiología de la resignificación y la compleja continuidad hermenéutica para garantizar una praxis crítica cuando las esforzadas labores sobre lo "residual" (Raymond Williams) aceitan unilateralmente la maquinaria hegemónica.

La negativa a esclavizar al indígena forma parte de aquella "heroicidad en el Paraíso": el "indio" es la tiranía de la sensibilidad, de las pasiones, del cuerpo, sobre la que el español europeo va a edificar (como ya lo ha hecho sobre sí y sobre otros con antelación) su dominio "ciudadano-civilizado" de las distancias. Sobre el "indio" tiene que triunfar la "forma" europea, y, gracias a esa empresa, Europa se reconstituirá a sí misma, tomando nuevas fuerzas desde sus raíces (griegas y hebreas: políticas - de la pólis- y edénicas). ¿No es un "héroe en el Paraíso" lo que Europa ha hecho de sí misma en cuanto imperio del "espíritu" y de la "inteligencia" sobre la corporalidad, sobre las pasiones, sobre las formas de convivir y de habitar? Si el Paraíso es nuevamente encontrado, frente

87 "La 'civilidad' -la civilidad europea- sólo puede garantizar la estabilidad de sus propias fundaciones negando la sustancialidad de otros mundos, de otras palabras, de otras narrativas." Hulme, Colonial, 1986, p. 156.

88 "La imagen del héroe multirrecursivo." Ibid., p. 153. 
a frente, no es más que para poner en marcha con nuevo vigor la tarea autoconstructiva. Esclavizar al "indio" sería no tener el espejo donde poder mirar la propia obra: la humanización del indígena interesa como europeización renovada de la totalidad (de ahí el énfasis español en el dominio sobre la gente que señalaba $\mathrm{Pa}$ tricia Seed, en un momento histórico en el que España necesitaba bendecir su reconquista). La dominación universal del héroe es justificada por su grandeza autoconsciente. Y, una vez puesto en marcha el motor, un universalismo misionario hace posible retirar el Paraíso hacia el pasado o relocalizarlo como remoto futuro para todos. El "héroe en el Paraíso" es el nudo cultural autofundante de Europa, con el cual ésta ata ahora a su antipodal "otredad": el "Nuevo Mundo". El "héroe en el Paraíso" se transforma en protector de la utopía mundial, que no es más que su propio tópos idealizado.

De este modo se debe relativizar la imagen todoroviana de Cortés como "experto en comunicación", "maestro de la improvisación": su "heroicidad" parece estar refugiada en los prejuicios más íntimos de su auditorio y de sus lectores; su silenciado fracaso en la manipulación de los mexicanos es la cizaña rizomática del desconcierto en medio del trigo de la victoria. La "heroicidad" de Cortés es ficcionalizada también por el mismo Todorov, aun cuando éste, paradójicamente, se propone la tarea deconstructiva del eurocentrismo en la construcción del "otro". Pero la "heroicidad" hegemónica sólo puede ser confrontada por las reapropiaciones de sus políticas desde otras tradiciones, subalternas; la resignificación textual operada por una crítica literaria de tradición formalista no es suficiente.

\section{LAS LABORES NOCTURNAS. \\ DE LA POÉTICA A LA DRAMáTICA DE LA REPRESENTACIÓN}

Edward Said, en su Orientalism, menciona, de un modo incidental, los términos en los que se expresaba el programa de la Société Asiatique durante el siglo XIX: ésta se proponía que los "frutos" de las "labores nocturnas" de los autores científicos ocupados en el estudio de Oriente, al ser editados, vieran la luz pública. Sólo los "frutos", pero sobre todo los "frutos".

Said se introduce con su linterna en el oscuro interior de esas "labores" y encuentra allí al "europeo privilegiado" en "Oriente", residiendo o viajando: "como un hablante nativo" y "como un escritor secreto"; ${ }^{89}$ su siempre "flexible superioridad posicional", 90 en todos los casos saliendo a flote del fondo de un "terror cósmico pascaliano": ${ }^{91}$ como expresara Blaise Pascal, "Le silence eternel de ces espaces infinis m'éffraie". ${ }^{2}$ "Labores nocturnas" que ocultan artificiosas seguridades ante la oscuridad, la inmensidad y la distancia, experimentadas como monstruosas amenazas; la lengua y la escritura son armas camufladas.

Me propongo acompañar la deconstrucción de esas "labores nocturnas" en la relación etnográfica, con vistas a liberar una nueva mirada sobre ese "otro" construído; pero, aun más allá de la mirada del "europeo privilegiado", me propongo volver a dimensionar aquellas "labores nocturnas" en su corporalidad (la "fuerza de trabajo"), no reconocida muchas veces

${ }^{89}$ Said, Orientalism, 1979, p. 160.

${ }^{90}$ Ibid, , p. 7.

${ }^{91}$ Ibid., p. 173.

92 "El silencio eterno de estos espacios infinitos me aterra." 
siquiera por el discurso antropológico ni por la práctica etnográfica: sombras en la medianoche que desarrollan batallas nocturnas en la factoría antropológica.

Sólo una antropología nocturna podría revertir la carta natal de una "ciencia sobre sociedades que desaparecen", tal como Adolf Bastian formulara inauguralmente la empresa antropológica en $1881 ;^{93}$ reversión para la cual no basta el sometimiento de la representación clásica, que nombra (inventa, poetiza) al Otro como "primitivo", a la dialéctica correctiva de un Otro concebido como presente y contemporáneo, tal como lo expresa el programa de Johannes Fabian, sino que es necesario dar entrada a la representación dramática en la escena etnográfica y combatir al discurso hegemónico del "otro" con sus propias mediaciones simbólicas. Un "otro" que, en su no desaparición, más aún, en su corporeización, "desalteriza" (descoloniza, en un movimiento marginal e inconcluso) la relación antropológica.

Ciertamente, no será una simple variación en la exterioridad de la relación etnográfica lo que permitirá denunciar las "labores nocturnas" del privilegio eurocéntrico y abrir paso discursivo a las "labores nocturnas" de fuerzas simbólicas subalternas. Si no ponemos en juego y en cuestión el mismo trabajo de representación y los modos de ésta, nos llevaremos varias sorpresas, sacando infinitamente al mismo "conejo", eterno, prolífico y numeroso, de entre las líneas del texto laboriosamente construido.

Bruce Kapferer, por ejemplo, confía ingenuamente en una antropología descolonizadora, en la medida en que ésta sea puesta en manos de etnógrafos autóctonos

${ }^{93}$ Fabian, Time, 1991. y en que éstos hagan un uso ideológico de la misma, de acuerdo con intereses nacionalistas. ${ }^{94}$ Hay aquí una derivación del discurso antropológico hacia el ámbito de la práctica, pero no se trata de la práctica interior y constitutiva de la antropología misma, de aquello que sucede en aquel espacio nocturno del encuentro con el "otro", sino de una práctica exterior, que, entonces, asume y reproduce las mismas relaciones de poder que pretende criticar.

La autoctonía no puede garantir más que una cierta y determinada pertenencia a las tradiciones (en la estructura y en el juego de fuerzas locales de poder), que habilita ciertas ventajas hermenéuticas. Pero dicha pertenencia sólo puede erigirse por algún artificio de una retórica oscura, en la única voz autorizada de la "región", sobre todo si ésta se autorrepresenta como totalizadora y unitaria en su narración. En el "otro" está el "Otro" construido, que hace parte del problema, y donde se cierra el nudo más invisible de la relación de poder.

Kapferer hace pesar demasiado la habilitación hermenéutica de la autoctonía. Esto lo lleva a constatar rápidamente que, a través de una "arqueología" del "conocimiento Sri Lanka", 95 como núcleo (según el autor) de la reproducción cultural y social regional, los antropólogos autóctonos hacen un "examen radical" de los fundamentos de la subjetividad del Sí Mismo

${ }^{94}$ Kapferer, "Periphery", 1990.

95 "Arqueología" en el sentido de Foucault, como configuración y tecnología de una episteme histórica que establece silenciosa y veladamente el modo, los objetos y las relaciones en las que puede y debe haber conocimiento. Véanse Foucault, Nacimiento, 1997; Palabras, 1996; Arqueología, 1997, y Orden, 1992. Aquí Kapferer lo aplica a una situación intercultural colonial. 
y del Otro. Dicha "arqueología" del "conocimiento Sri Lanka" iluminaría, "por refracción", una arqueología de las realidades metropolitanas y coloniales, sus teorías y disciplinas del conocimiento, entre las que ha sido establecida la antropología misma. ${ }^{96}$ Pero este estudio comparativo de los procesos de constitución de los conocimientos "occidental" y "Sri Lanka" esconde, en la aparentemente única y armoniosa tradición propia, la misma hegemonía colonialista de la que busca diferenciarse: la multiplicidad, los conflictos y las luchas por el poder entre los grupos $y$ tradiciones locales son (a)calladas por esta "autoctonía" y su discurso. Kapferer descuida, en el paso de Occidente a la posición local colonial, que Foucault se refería con episteme a una formación hegemónica. Una "labor nocturna" del privilegio en medio del contexto pretendidamente poscolonial.

Johannes Fabian, en cambio, critica la representación cognitiva omnisciente por parte del etnógrafo, ${ }^{97}$ que ha dispuesto del Otro como "salvaje" (no-civilizado), como "pasado" (no presente) y como "objeto" (no sujeto), ${ }^{98}$ otorgándole así un estatus cultural: "cultura" como el order-outof-chaos -"orden-emergiendo-del-caos"en el cual la distante "alteridad" se torna comprensible, aunque más no sea traduciendo su "salvajismo" y "barbarie" a una fase protozoaria de la hipérbole evolutiva. La crítica antropológica debe desplazarse, para Fabian, "de la clasificación a la confrontación" y "de la representación a la praxis", para superar el "visualismo de la representación" (en lo que sigue la crí-

\footnotetext{
96 Kapferer, "Periphery", 1990, pp. 300-301'.

${ }^{97}$ Fabian, Time, 1991 , p. 192.

${ }^{98}$ Ibid., p. 195.
}

tica realizada por Richard Rorty). La experiencia del trabajo de campo es una praxis comunicativa que debería tener consecuencias en las otras fases de la producción del conocimiento antropológico, y que debería hacer ver como reducción de dicha experiencia la instancia contemplativa final de una representación del Otro. ${ }^{99}$ La práctica etnográfica es una acción comunicativa que abre la "capacidad universal de simbolizar" en una dirección no cognitiva (en el sentido de no concluyente en el representar).

El énfasis de Fabian está puesto en evidenciar el suelo práctico-comunicativo de toda relación etnográfica, sobre el cual se erige como monumento fundacional de la dominación colonial el representacionismo objetivador, distanciador, privilegiador del "sujeto cognoscente": "labor nocturna" del colonizador sobre las "labores nocturnas" de los "otros" presentesausentes. Fabian busca dar al representar un lugar más modesto y menos imperial en una teoría del conocimiento; aunque no al extremo de negarlo de un modo radical. ${ }^{100}$ Es decir, no se trata de rechazar la representación, cuya consecuencia inevitable sería, según el autor, la "no escritura" (not-uriting), el "silencio gráfico". ${ }^{101}$ Notwriting debería ser interpretado, enfatiza Fabian, más bien en el sentido de un diálogo continuo con el "otro", sin descansar jamás en la escritura, que sería tan sólo una de las mediaciones provisorias de ese diálogo. Sin embargo, esta dialéctica a la que son sometidas las representaciones, siempre en construcción y revisión, oponiendo unas a otras, sustituyendo secuen-

\footnotetext{
99 Ibid., p. 202.

${ }^{100}$ Ibid., p. 209.

${ }^{101}$ Ibid., p. 214.
} 
cialmente unas por otras, no libera mediaciones y modos no linguiísticos del significar. La extensión del "simbolizar" más allá del "representar" se daría, para Fabian, en la praxis, suelo interaccional de toda representación. Pero, en la dirección inversa, del "simbolizar" como confrontación en la praxis al "representar", no se encontraría más que el acento en una interacción achatada contra el universalismo del "representar" lingüístico-escriturario. Aquella dia-léctica fabiana tiene la ventaja de sumergir a la antropología, en cuanto "proceso de otración" (the process of othering), en una crítica permanente e inacabada ("proceso de desotración"), que, inscribiéndose en un deconstruccionismo infinito, no permite al menos liberaciones definitivas ilusorias de optimismo poscolonial. Pero el límite de esa dialéctica es que no existiría otra praxis comunicativa que la que acompaña, excediéndolo, al representar lingüístico, consagrado (fetichizado) en la tradición dominante greco-europeooccidental como modelo de todo "representar" y de toda construcción de significación: he aquí la cápsula intocada del tal "deconstruccionismo", "labor nocturna" aún (al mejor estilo de la Société Asiatique) del privilegio europeo.

En este vaivén encarcelado (entre praxis y representación), Fabian enfatiza un poder práctico liberador que no alcanza a tener ni una densidad mayor que el ejercicio de la negación de las representaciones anteriores, ni una complejidad alternativa a las representaciones lingüístico-escriturarias: un sucesivo estrellamiento de los espejos contra el suelo; como un narciso en movimiento, hegeliano, circulando en torno de su ombligo denegado, planeta monótono. Pero, ¿hasta qué punto los espejos son destruidos, y no ocultan, más bien, un discur- so unilateral de espejos rotos? Dicho de otro modo: ¿qué garantiza que la dialéctica continua con el Otro conduzca a una mayor proximidad comunicativa con Él, y no a un alejamiento, si no se está dispuesto sino a sustituir imágenes en una pantalla preestablecida como medio único y universal de comunicación? Porque, según el mismo Fabian, el "proceso de desotración" llevado adelante a través del diálogo continuo de los sujetos que participan en la relación etnográfica, no termina en una mera declaración de contemporaneidad del Otro, sino que debe prolongarse en la crítica de las representaciones en cuanto crítica dialéctica (práctica, no especulativa) de las ideologías. Crítica de las representaciones que debería abrirse, por lo tanto, a un reconocimiento de significaciones alternativas (respecto del representar lingüístico) y poner en escena el conflicto de mediaciones y modos de significar, los trabajos de representación y las luchas en el poder de representar con una mayor densidad intercultural.

Una vía fenomenológico-deconstructiva que se desarrollara en el medio etnográfico abriría hacia una interculturalidad comunicativa, pero Fabian escoge una vía "deconstructiva" restringida que se desarrolla en los (re)encuentros posetnográficos, hacia un proceso de liberación sin término del Otro (pre)construido y dominado. No se trata de un deconstructivismo especulativo, sino práctico y dialéctico: en la continua conversación con el Otro, ${ }^{102}$ en una dinámica bermeneutic-dialectical -"hermenéutico-dialéctica"-, que acumula la demolición de las propias representaciones de la "alteridad". Dicho "deconstructi-

${ }^{102}$ Ibid., p. 222. 
vismo" no hace más que cuestionar todas y cada una de las representaciones, sin cuestionar la supuesta universalidad del único modo de representar dialectizado. Por más que se enfatice el reconocimiento del Otro, que nunca está limitado a sus representaciones ${ }^{103}$ ese Otro es capturado y liberado (siempre y exclusivamente) en la representación linguística. Representaciones envueltas en praxis, provisorias en la agilidad dialéctica; en una dialéctica hegeliana intersubjetiva, dialogizada; palimpsesto que sigue siendo objeto siempre de una lectura conceptual en la tradición lingüística logocéntrica occidental. Porque la praxis dialógica rompe las representaciones, pero ella misma parece ser puro contacto transparente, sin espesor, lo "no representado". Fabian nos pone ante una dialéctica cerrada entre representaciones y praxis, donde sigue quedando de un solo lado y en un solo plano las posibilidades de racionalidad. ¿Se trata una vez más de lo sublime, de una teología negativa del Otro, pero que termina legitimando los accesos culturales etnocéntricos a la "Gran Ausencia"? ¿Estamos ante una ontología heideggeriana de la escucha del Otro, articulada en la temporalidad hermenéutica, y destinada a su fracaso por la ilusión de "verdad" que crea, por el reconocimiento insistente y empecinado del Otro dentro del (eurocentrismo del) lógos y del lenguaje gramaticalmente constituido, impuesto como mediación comunicativa exclusiva o privilegiada? "Labores nocturnas" no reconocidas en este paradójico "reconocimiento crítico" del Otro.

Fabian busca transformar la etnografía en una praxis capaz de hacer al Otro presente, antes que hacer representaciones predicadas en su ausencia. ${ }^{104}$ Pero este "presente" está demasiado impregnado de la propia historia del antropólogo como para establecer una comunicación más abierta e inestable de acontecimientos. Fabian queda encerrado en la unicidad de la representación lingüística: entre la "ausencia" total del Otro en la representación que lo sustituye y la "presencia" mesiánica del Otro como manifestación destinada a ser capturada en la finitud de una nueva representación precaria. Cuando ya no hay lenguaje (representativo), parece haber sólo silencio fantasmal: de la boca a los ojos, en un aire etéreo, que es el dominio eidético de las imágenes más allá de las palabras, aparece el Otro a una mirada muda; un platonismo dialógico en el campo etnográfico, que rodea progresiva y vanamente de lenguaje su discurso en torno del sol fulgurante, como una psyjé encandilada, una y otra vez. Lógos y éidos siguen confabulando en la tradición platónica eurocéntrica como subtexto práctico de esta nueva etnografía.

Sin embargo, en esa dialéctica etnográfica debe haber algo más que imágenes y palabras en el aire. Porque, si no, esta "presencia" del Otro no tendría ninguna efectividad crítica liberadora en el orden práctico. Afirmar simplemente la necesidad que tiene una etnografía de ser revisitada con frecuencia no sería en absoluto original y se trataría de algo casi tan antiguo como el quehacer representador de la antropología misma. Por eso, dicha "presencia" tendrá que poner en juego alguna mediación excluida o imprevista, a fuerza de agotarse, si no, entre palabras e imágenes, en cada inevitable despedida del etnógrafo, o aún antes.

${ }^{104}$ Ibid., p. 223. 
Que la escritura sea en definitiva el quehacer de los antropólogos, ${ }^{105}$ que escribir antropología signifique elaborar "construcciones con el tiempo" ofreciendo relatos que relacionan culturas, no debería concluir en la hegemonía de un significar sobre sus otros múltiples modos, definitiva (y, con otro nuevo privilegio, ahora crítico), consagrada. La declaración fabiana de total "contemporaneidad" debe ser acompañada por el programa de "desalterizar" la relación etnográfica a través del reconocimiento de una diferencia alternativa comunicacional. Porque la homologación temporal que ésta ocultamente supone from then to now -"del entonces al ahora-, pero, ¿el "ahora" de quién?; ¿cuál es la densidad de sentido temporal de ese "ahora"? son preguntas que se clavan en mí ante los rápidos pases críticos de Fabian, y la liquefacción de toda singularidad en una representación infinitamente renovada, pueden dar, no obstante y a su pesar, continuidad a la postergación del Otro. Del "entonces" (then) al "ahora" (now), se filtra aún la temporalidad propia del etnógrafo y su mundo; mantener la "distancia" (there and then, "allá y entonces") no es la única forma de la dominación, ni la mutua presencia garantiza un mayor reconocimiento crítico después del concepto gramsciano de "hegemonía": no basta aproximar los términos para alterar una relación.

El propio poder comunicacional diferencial del "otro" es el que lo "desalteriza", y su reconocimiento es lo que "desalteriza" la relación etnográfica: la "diferencia" es una complicidad de ambos (y supone un poder y un temor simultáneos y no equilibrados). Una dialéctica robusta e incontro-

${ }^{105}$ Ibid., p. 236. lable da al "otro" no sólo el polo de la "experiencia" (donde se niegan la escritura, la narración, las categorías; en definitiva: las representaciones de la "otredad", para Fabian), sino el de la significación alternativa de la "experiencia": un poder comunicacional radical, un trabajo de representación, una lucha irreductible, una disputa de la hegemonía escrituraria de la significación que irrumpe en el dominio mismo de la escritura, precisamente donde y cuando en ella el significar alternativo es (con premura de parches y sustituciones) traducido-trasvasado. Es demasiado pronto para abandonar este espesor intercultural en nombre de cualquier "igualación".

Porque aun el mismo concepto de "representación", en la propia tradición europea, puede dar lugar a la doble comprensión histórica de la "mímesis" griega: en cuanto mera "copia" y en cuanto "ampliación" significativa. Este segundo sentido guarda relación con la dramatización teatral como modelo de la actividad artística. En analogía con este segundo sentido tomo el término "representación" cuando hablo, desde el título de este capítulo, de una "dramática de la representación". Hans-Georg Gadamer ${ }^{106}$ ha mostrado la intensa densidad comunicativa de esta "representación" a partir de la experiencia estética teatral como acontecer relevante de significación, como "incremento de ser" que enlaza con el conocimiento desde el plano existencial. El arte, el habla y la escritura, desde el develamiento de ese "representar" dramático, se muestran como escenarios diversos y alternativos de "representación" en el interior de la tradición europea. La etnografía pone en escena, también, representaciones alternativas,

${ }^{106}$ Gadamer, Verdad, 1984, parte 1. 
pero no sólo nuevas, sino (con una intensidad de alta frecuencia que pone en emergencia el sentido común) otros modos de significación y que además pertenecen a tradiciones diferentes; no la mera confrontación práctica de un único modo de representación con la "experiencia", como enfatiza reductivamente Fabian. Se trata, entonces, de abrir el campo de acción, en la práctica etnográfica, a diversos modos de construcción de sentidos; no sólo de liberar un modo pretendidamente exclusivo de significación; se trata de liberarse también de esa exclusividad, en la que aún trabaja nocturnamente el privilegio y la superioridad.

Si ahora, gracias a la radicalidad de la empresa filosófica "deconstruccionista" (como valora Fabian), se ha puesto a la luz nuevos pliegues del silenciado privilegio europeo, se ha de poner a la luz también, y reconocer en acción, gracias a una nueva etnografía deconstructiva, la acallada potencia comunicativa (y política) de quienes, bajo la hegemonía de la representación lingüístico-escrituraria, han desarrollado incansablemente la lucha por la significación en las mediaciones alternativas que reúno bajo el nombre de "dramática de la representación". "Dramática de la representación", por el relieve significativo del gesto, del cuerpo, de la acción, y la pertenencia del lenguaje, de la visibilidad y del sentido a ese relieve. Mediaciones con las cuales el "otro" se ha hecho "presente", o mejor, ha complicado la "flecha del tiempo" hiriendo el sentido común o escabulléndose por sus tramoyas, a pesar de que se le han sobrepuesto las representaciones de la hegemonía.

La posición etnográfica de Mark Hobart ante la acción social balinesa, por ejemplo, camina en esta dirección. ${ }^{107}$ Una propuesta que va más allá de las expectativas occidentales de constitución, de participación social y política del "otro", colonizado y categorizado; expectativas que, como vimos, muestran una permanencia en el "representacionismo" aun por parte de los partidarios à la Fabian de la deconstrucción de las representaciones (montando a ese carro viejo la migración radical de "realidad" y referencialidad hacia una mera "invención"), y para quienes, de un modo aún más solapado, la prescripción occidental "representa las nuevas condiciones de la representación de las representaciones de los 'otros"'. 108

Frente a ello, la "nueva etnografía", según Hobart, pone el énfasis en las otras mediaciones de la acción social, no representables al modo concluyente de la visibilidad ("presencialidad") linguíístico-escrituraria, por su carácter constructivo no clausurado, y, por eso mismo, en los límites del control hegemónico. En el caso de

107 Hobart, "Who", 1990, p. 306.

${ }^{108} \mathrm{La}$ "universalidad" de la representación lingüística lleva, en su carrera tecnológica dominante, hasta la hiperconstrucción del "simulacro" (véase Baudrillard, Cultura, 1993); pero éste no es tanto cuestión de imagen cuanto de formato (modo de significar altamente formalizado): el Otro "hiperreal" es, ciertamente, una extremación del representacionismo linguístico, pero la crítica queda a mitad de camino si sólo se le contrapone una masa amorfa, omnidependiente, devoradora, sumergida en una inmensa "sombra" y en un silencio estelar apocalíptico. "Todo o nada", parece decir la sospechosa alternativil, que sigue afirmando la única accesibilidad clásica al significar por detrás de su negación ostentosamente declamada. Al Otro "hiperreal" se le contraponen, más bien, en combate, los modos de significar de los otros con sus mediaciones: políticas del significar. 
la acción social balinesa, Hobart señala su multiagencialidad y su creación del contexto, siempre abiertas, y lo muestra en la significación de los términos en que se expresa dicha acción y en la performance ritual de las escrituras sagradas.

Con el mismo énfasis recojo la reconstrucción que realizan Jean y John Comaroff de la lucha de los tswana contra la hegemonía de los símbolos en Sudáfrica durante el siglo XIX y comienzos del $\mathrm{XX} .{ }^{109}$ Más allá de lo previsible, en el contexto de una flexibilidad dialéctica extremada y de la multiagencialidad de los poderes de la dominación y de las fuerzas de los autóctonos, los tswana hacen historia con sus propias mediaciones culturales: graphic verbal and gestural trops ("giros gráficos verbales y gestuales"). ${ }^{110}$ Los autores extienden la "poética de la historia" a un hacer historia alternativa respecto de la colonización gramatical, en los márgenes paradójicamente más abarcativos, más frágiles, más sutiles y más vulnerables de la hegemonía: los giros verbales y corporales de los actores coloniales. Así, las "políticas del agua" muestran una comunicación conflictiva, por detrás de la visibilidad occidental, entre el dominio de la "gerencia ritual" (ritual management) de las "técnicas simbólicas indígenas", por parte de los tswana, y el dominio de la "gerencia técnica" (technical management) con técnicas e instrumentos secularizados, por parte de los misioneros cristianos colonizadores. ${ }^{111}$ La gestualidad ritual tswana se muestra

${ }^{109}$ Comaroff y Comaroff, Revelation, 1991, vol. I, y Ethnography, 1992.

${ }^{110}$ Comaroff y Comaroff, Revelation, 1991, vol. 1, p. 35.

11.. Comaroff y Comaroff, Etbnograpby, 1992, p. 242. políticamente abierta a otros saberes y técnicas, no descalificados de antemano; los tswana, en todo caso, están dispuestos a apropiarse del poder diferenciado y competitivo (poder cultural y técnico) introducido por los blancos en su mundo. ${ }^{112}$ "Labores nocturnas" que no son sólo, por tanto, el cumplimiento del trabajo impuesto por la dominación, sino batallas nocturnas en las fronteras más leves y determinantes de la hegemonía colonizadora.

\section{EL SAPO Y LA COBRA. \\ LA SEMIOPRAXIS SUBALTERNA}

Una voz indígena, Augusto Paulino, indio Krenak, expresaba, en un encuentro realizado por la Comissão Pró-Indio de São Paulo, en esa ciudad brasileña, en 1981:

peço a todos os irmãos que estavam dizendo aí, que não enfraqueçam, não. Consigam a batalha de frente, porque o sapo que para, a cobra come ele. O sapo sempre mais um pulinho à frente. Nunca se para, não, porque tem 22 anos que eu venho sufrendo, mas agora, se Deus quiser, eu vou em frente, nem que seja pulando un metro, amanhã eu pulo dois e, se Deus quiser, eu chego lá. Mesmo para deixar pros meus filhos, meus sobrinhos, meus primos, pra minha comunidade, eu quero deixar alguma coisa. ${ }^{113}$

112 Ibid., pp. 244-245.

113 "Pido a todos los hermanos que estaban hablando ahora que no desfallezcan, no. Den la batalla yendo adelante, porque: sapo que para, la cobra se lo come. El sapo (dando) siempre un pequeño salto al frente. Nunca se detiene, no, porque hace 22 años que yo vengo sufriendo, mas ahora, si Dios quisiera, yo voy adelante, aunque sea saltando un metro, mañana salto dos (metros) y, si Dios quisiera, llego allá. 
En nuestras naciones poscoloniales, con frecuencia las ciencias sociales y humanas han pasado por alto, en su afán crítico, el reconocimiento de la dinámica subalterna que, "paso a paso" y en múltiples direcciones, enfrenta los astutos acorralamientos de la hegemonía en una práctica no controlable de resignificaciones y reapropiaciones. Más allá de la pretendida homogeneización, política dominante heredera del colonialismo europeo, los dominados reponen la heterogeneidad: operan desde sus propias tradiciones y crean sentidos irreductibles; mientras, en la mirada del intelectual y del científico, sin embargo, sigue triunfando la homogeneidad, en continuidad con una lectura plana y eurocentrada de la experiencia colonial. ${ }^{114} \mathrm{Un}_{\mathrm{n}}$

Al menos para dejar para mis hijos, mis sobrinos, mis primos, para mi comunidad, yo quiero dejar alguna cosa." Ramos, "Vozes", 1990, p. 121.

114 "Semio-praxis", "significación-acción", "orientación-significación de la acción", "semiología de las prácticas", es la perspectiva teórico-metodológica en la que vengo trabajando desde hace algunos años. Véanse Grosso, "América", 1989; "Ritual", 1994; "Poder", 1994; "Dibujar", 1994; "Suerte", 1994; "Ritual", 1996; "Estructura", 1996; "Indios", 1997a; "Indios", 1997b; "Identidades", 1997; "Políticas", 1997; "Indios", 2001; "Reclinando", 2002; "Radicalidad", 2002; "Interculturalidad", 2003; "Extranjero", 2003; "Cuerpo", 2004; "Modernidad", 2004; "Cuerpo", 2005, y "Público", 2005. En ellos enfatizo una posición crítica construida en la relectura de la estetización radical kantiana; en su reapropiación por las reacciones antihegelianas del siglo xIX: el joven Marx, Kierkegaard, Nietzsche; en el relieve creciente y primario dado a lo cultural en los procesos sociales y la acción política: Gramsci, Bajtin, Edward P. Thompson, Raymond Williams; en la deriva de la lingüística a la práctica semiológica: Peirce, Wittgenstein, Foucault, Deleuze, Kristeva, Barthes, Guattari, Derrida; en la fenomenología del cuerpo de MerleauPonty; en la sociología comprensiva de Georg Sim- caso paradigmático al respecto es el del "colonizado" en la dialéctica (acumulativa) de la "situación colonial", según Albert Memmi. ${ }^{15}$ Si bien se indica una multiplicidad de "colonizadores", el "colonizado" no encuentra las figuras políticas de su diferenciación; éste no es ya de ningún modo un "sujeto de la historia", toda memoria de libertad le resulta distante, se halla estancado entre los propios valores tradicionales momificados y la estructura colonizadora; ${ }^{16}$ su universo es el del vencido, ${ }^{117}$ sin memoria; ${ }^{118}$ permanece adherido a la colonización, ${ }^{11}$ hasta que aquella "situación" se satura al punto de desencadenar su instancia superadora: el "nacionalismo". Este nuevo momento, salida necesaria e inevitable, en el ingenuo optimismo doble del autor, es visto como la completa desaparición del coloniaje.

No es así en las investigaciones del grupo indio reunido bajo el nombre de Subaltern Studies. Ashis Nandy, por debajo de la imposición británica de “jerar-

mel, Alfred Schutz, Erving Goffman y Anthony Giddens; en la práctica etnográfica y el estudio de sus revisiones críticas en la antropología del siglo $\mathrm{xx}$ : Geertz, James Clifford, Renato Rosaldo, Paul Rabinow; en el estudio de las prácticas sociales de Pierre Bourdieu y Michel de Certeau; en la geocultura fenomenológico-hermenéutica de Rodolfo Kusch; en las relecturas gramscianas de Ernesto Laclau, Chantal Mouffe, Jean y John Comaroff, Gayatri Spivak y los Subaltern Studies; todos ellos reapropiados en una crítica social intercultural en nuestros contextos poscoloniales. Esta perspectiva teórico-metodológica de una semiología de las prácticas como teoría social crítica es desarrollada in extenso en un libro en preparación.
115 Memmi, Colonizer, 1965.
${ }^{116}$ Ibid., p. 92.
${ }_{17}^{17}$ lbid., p. 100
${ }^{118}$ Ibid., p. 103
${ }^{119}$ Ibid., p. 88. 
quías seculares" -nuevas categorías impuestas tales como las relativas al sexo ("masculinidad" sobre femineidad, androginia y homosexualidad) y a la edad ("adultez" sobre infancia y ancianidad), que reemplazan las categorías tradicionales- levanta el velo extendido por las ciencias sociales sobre la "otra India", la olvidada mayoría. ${ }^{120}$ Esta "otra India" ha incorporado, digerido lo Occidental: ${ }^{121}$ ella es capaz de hacer un uso instrumental de Occidente para sus propios propósitos, se mueve entre la hipocresía cultural y la habilidad para subvertir. Esta India mayoritaria posgandhiana no es, según el autor, "premoderna" ni "antimoderna"; es "no moderna": sostiene un universalismo no moderno que ve a la India occidentalizada como una subtradición.

Con una mayor profundidad analítica y un pensamiento no dicotómico, Partha Chatterjee señala, en el proceso de construcción del nacionalismo "oriental" en la India, una inconmensurabilidad y un relativismo intercultural que pueden ser acogidos por una antropología que reconozca racionalidades alternativas. ${ }^{122}$ Los tres momentos de dicha construcción son representados por sendos intelectuales autóctonos: Bankim, Ghandi y Nehru. El primero ejemplifica el momento de creación de la "nación"; Ghandi personifica y dirige el momento de distinción y separación de la "nación" (campesinado y líderes) respecto del Estado nacional; Nehru cierra $y$ abre el momento en que se enfrenta la necesidad de un Estado-nación reconstruído, sometiendo al campesinado bajo control. Pero el momento de mayor relevancia

\footnotetext{
${ }^{120}$ Nandy, Intimate, 1983.

${ }^{121}$ Ibid., p. 75.

${ }^{122}$ Chatterjee, Nationalist, 1993, p. 6.
}

en el texto de Chatterjee es el así llamado "momento de maniobra" y que refiere al discurso nacionalista de Ghandi. Es el momento clave en el que, en el recurso al pensamiento nacionalista y el rechazo del discurso colonialista, se construye la diferencia y se critica al racionalismo ilustrado. ${ }^{123}$ Chatterjee lo llama "de maniobra" porque se produce en la coyuntura de la independencia colonial y la construcción de la nueva "nación" según un nuevo modelo; momento de la tarea intelectual y conductora de Ghandi, pero también del "ghandismo popular". Si bien el "comunalismo" ghandiano es interpretado como passive revolution (expresión tomada de Gramsci: "revolución pasiva"), sin embargo, el campesinado no participa en vano del movimiento. La burguesía, que aspiraba a la hegemonía dentro del nuevo Estado-nación, se apropia de la movilización del campesinado subalterno, ${ }^{124}$ negándole a la vez una participación autónoma en la nueva política nacional, distanciándolo definitivamente del Estado, sin mediación política alguna, sólo cultivando respecto de él una actitud moral de "responsabilidad" (esto es la "revolución pasiva"). El campesinado, por su parte, se apropia, mediante la ideología ghandiana, del discurso nacionalista, sobrepasando en varios casos la restricción (mitificadora de la propia tradición autóctona) impuesta por la "no violencia" ${ }^{125}$ y reinterpretando de múltiples maneras el "mensaje del Mahatma". ${ }^{126}$ Así, el "momento de maniobra" es de agenciamientos heterogéneos.

\footnotetext{
${ }^{123}$ Ibid., p. 41.

${ }^{124}$ Ibid., p. 100.

125 Ibid., p. 124.

${ }^{126}$ Ibid., p. 125.
} 
Gayatri Spivak radicaliza, en su valoración de los Subaltern Studies, el reconocimiento de la praxis de resignificaciones-reapropiaciones subalternas. ${ }^{127} \mathrm{El}$ movimiento indiano es leído como "deconstruccionismo": la tarea de la historia es reconocer la agencialidad por parte del "insurgente" del cambio operado por la colonización. ${ }^{128}$ La disciplina histórica no desciende sobre un mundo sin interpretar, "no cae de repente sobre un suelo virgen"129 (está inscrita en una "hermenéutica doble", diría Giddens); lo que ésta encuentra, más bien, es el poder de un significar sobre otro, hegemonizando su "querer decir": una lucha de representaciones y significaciones, de modos de representar y de significar. Los Subaltern Studies proponen una "teoría del cambio" como "continua cadena de signos": ${ }^{130}$ rupturas y uniones de la "cadena" como operaciones simbólicas, más allá de la definición y más allá de una "conciencia" social constituida gramaticalmente en cuanto "autoconciencia". ${ }^{131}$ Estas reinterpretaciones-reapropiaciones, en tanto son vistas como "fallas" en el plano cognitivo (tropos de desplazamiento, que conservan y superan), no son ubicables, según un criterio evolucionista, en un "nivel o estadio de conciencia" de una clase social. ${ }^{132}$ Son las "exitosas fallas cognitivas" de la insurgencia. ${ }^{133}$ Aún más, mientras "falla" y "éxito"

${ }^{127}$ Spivak, Other, 1988.

${ }_{128}^{28}$ Ibid., p. 197.

${ }^{129}$ Ibid., p. 129.

130) Nietzsche, Genealogía, 1986, tratado segundo, parágrafos 11,12 y 13.

${ }^{131}$ Spivak, Other, 1988, p. 198.

132 Ibid., p. 199.

133 Working mistakes (errores que funcionan, provechosos) que Marshall Sahlins reconoce en la inter- pertenecen a una teoría del conocimiento determinada, en el caso del "subalterno" se trata también de otro "conocer", $y$, en este sentido, son "irreductibles": son otros "tropos" que articulan otra relación entre praxis y conocimiento. A estos dos aspectos, práctico y gnoseológico, se refiere Spivak cuando afirma que las "fallas cognitivas" son irreductibles; y forman parte del programa, científico, social y político a la vez de una "deconstrucción de la historiografía". Así, lo "subalterno" se mueve creativamente en la "complicidad" resignificadora-reapropiadora y en la actividad "parasitaria" respecto de la ideología de la dominación; ${ }^{134}$ extensión y aplicación de aquella frase de Gautam Bahdra recogida por la autora: "It is in the unfreezable dynamic of slang that subaltern semiosis hangs out."135

Estamos en las antípodas de la que podríamos llamar "antropología del simulacro", al modo de la que representa, por ejemplo, Terence Turner. ${ }^{136}$ Los kayapo de Gorotire, para el autor, antes de su pertenencia a la nación brasileña, habrían estado anclados en una visión del mundo ahistórica y acultural. ${ }^{137}$ La sociedad nacional, al abrazar junto con ellos otros grupos indígenas, habría forjado su "conciencia étnica" (no meramente "cosmológica", es decir: de una humanidad única en el centro del mundo) en virtud de la contra-

acción de los nativos con el capitán Cook en las islas del Pacífico a finales del siglo Xvill. Véase Sahlins, Historical, 1981; Islands, 1985, y How, 1995.

${ }^{134}$ Spivak, Other, 1988, p. 221.

135 "Es en la incongelable dinámica de la jerga local que la semiosis subalterna se descuelga." Ibid., p. 263.

${ }^{136}$ Turner, "Representing", 1991.

${ }^{137}$ Ibid., p. 299. 
posición, la reunión con los otros "indios", y la amenaza cernida sobre ellos. ${ }^{138}$ Los "antropólogos" (por otro lado, generosamente definidos, integrando cuanto $\mathrm{cu}-$ rioso se asomara por allí) habrían dado a los kayapo su "cultura" y el valor político de ella. Éstos (filántropos misioneros) gastan dinero, arriesgan sus vidas, les dan bienes y medicinas, son mediadores de la preocupación (!) y del aporte material (!) de los centros metropolitanos, y son un advenimiento liberador al hacer un nuevo tipo de trabajo de campo: "observación participativa". Por eso, han sido objeto de sospecha y hostilidad por parte de los dominadores (v. g. el servicio indígena gubernamental y los - "otros"- misioneros). Ahora, los indios se han vuelto antropólogos de su propia "cultura" y el (anterior) antropólogo ha devenido de "observador" a "actor": "hace parte integral del proceso que observa", es un "instrumento". ${ }^{39}$ Además, Occidente y el (heroico) antropólogo les habrían dado a los indígenas los medios técnicos que les posibilitan autorrepresentarse: filmadoras, cámaras fotográficas, grabadores. La donación ha sido total (igualmente y proporcional la pasividad indígena). Occidente, la sociedad nacional y la antropología habrían puesto a los kayapos (seguramente como etnia privilegiada) en camino de su propia liberación, con una potencia de impulso tal que ya habrían resuelto las constricciones mayores para su independencia: no sólo declarando su autonomía comunal, sino cuando los indígenas han logrado el control local sobre los principales modos de articulación con los sistemas nacional y mundial (!). ${ }^{140}$

\footnotetext{
${ }^{138}$ Ibid., p. 296.

${ }^{139}$ Ibid., p. 305

${ }^{140}$ Ibid., p. 302.
}

Y todo gracias a la antropología: ¡una antropología a todas luces descolonizadora!

Retomo, para concluir, la hipótesis (y el programa de investigación que de ella se desprende) que Alcida Rita Ramos, sin duda en mayor sintonía que la "etnografía" de Turner con las palabras iniciales de Augusto Paulino en este capítulo, enuncia: hasta en medio de las formas más viles de dominación (esclavización, expediciones punitivas, explotación de mano de obra, usurpación de tierras, transmisión de enfermedades), no hay sociedad indígena que haya sufrido pasivamente las consecuencias del contacto sin ejercer algún tipo de reacción creativa. ${ }^{141}$ Ciertamente, este poder de agenciación, resignificadorreapropiador, subalterno dimensiona políticamente la mítica, la ritualidad y las estrategias de la vida cotidiana indígenas ${ }^{142} \mathrm{y}$, agrego, de los medios populares. Labores nocturnas de una praxis crítica no necesariamente ni por lo común "revolucionaria". Y el antropólogo, el científico social, en cuanto aprendiz, ${ }^{143}$ antes de ostentar la posesión de un discurso liberador, reconoce la práctica ya existente en esas luchas, y participa insoslayablemente, en un sentido u otro, en ellas.

Espero haber puesto suficientemente de relieve en estas páginas que la relación científica y la oscura relación pedagógica en contextos interculturales poscoloniales (y en todos) tienen una dimensión política primaria; como, así mismo, que la acción política tiene, en el campo epistemológico y en la "hermenéutica doble" en que se inscribe la ciencia social, un escenario de luchas que no es el territorio exclusivo de los

\footnotetext{
141 Ramos, "Vozes", 1990, p. 139.

${ }^{142}$ Ibid., p. 142.

${ }^{14.3}$ Ibid., p. 143.
} 
científicos, sino el de los científicos en medio de los actores sociales que interpretan y gestionan la vida social en su semio-praxis cotidiana. Michel Foucault, Jacques Derrida, Pierre Bourdieu y Rodolfo Kusch tal vez hayan sido leídos, pero, a juzgar por la siempre recurrente y astuta autorreferencialidad académica y por la impunidad de los grandes y pequeños programas de intervención social y de desarrollo, ciertamente no han sido ni suficiente ni, mucho menos, críticamente escuchados.

\section{BibLIOGRAFÍA}

-Baudrillard, Jean, Cultura y simulacro, Kairós, Barcelona, 1993 (1978).

-Bond, G. y A. Gilliam (orgs.), The Social Construction of the Past. Representation as Power, Routledge, Londres, 1994.

-Chatterjee, Partha, Nationalist Thought and the Colonial World, University of Minnesota Press, Minneapolis, 1993.

-Clendinnen, Inga, " Fierce and Unnatural Cruelty': Cortés and the Conquest of México", Representations, núm. 33, 1991, pp. 65-100.

-Clifford, James, The Predicament of Culture. Twentieth-Century Ethnography, Literature, and Art, Harvard University Press, Cambridge, Massachusetts y Londres, 1988.

Comaroff, Jean y John Comaroff, Of Revelation and Revolution, University of Chicago Press, Chicago, 1991, vol. I.

- Etbnography and the Historical Imagination, Westview, Boulder, 1992.

-De Certeau, Michel, L'écriture de l'Histoire, Gallimard, París, 1975.

, Heterologies. Discourse on the Other, University of Minnesota Press, Minneapolis, 1986.

-Derrida, Jacques, El monolingüismo del otro, o la prótesis de origen, Manantial, Buenos Aires, 1997 (1996).
-Fabian, Johannes, Time and the Work of Anthropology, Harvard Academic Publishers, Filadelfia, 1991.

-Fardon, Richard (org.), Localizing Strategies, Westview, Los Ángeles, 1990.

-Foucault, Michel, Vigilar y castigar. Nacimiento de la prisión, Siglo XXI, México, 1984 (1975).

, El orden del discurso. Lección inaugural en el Collège de France, 2 de diciembre de 1970, Tusquets, Buenos Aires, 1992 (1970).

- Las palabras y las cosas. Una arqueologia de las ciencias humanas, Siglo XXI, México, 1996 (1966).

$\longrightarrow$ - El nacimiento de la clínica. Una arqueología de la mirada médica, Siglo XXI, México, 1997 (1963).

- La arqueología del saber, Siglo XXI, México, 1997 (1969).

-Gadamer, Hans-Georg, Verdad y método. Fundamentos de una bermenéutica filosófica, Sígueme, Salamanca, 1984 (1975).

-Giddens, Anthony, Las nuevas reglas del método sociológico. Crítica positiva de las sociologias comprensivas, Amorrortu, Buenos Aires, 1997 (1976; 1993).

-Grosso, José Luis, "América: caminos abiertos. Kusch y el sujeto épico americano", Santiago del Estero, 1989, inédito.

—_, "Ritual y acción social. Un diálogo con Edmund Leach y Victor Turner", Brasilia, 1994, inédito.

—_, "Poder y representación: el performativo etnográfico", Brasilia, 1994, inédiro.

— "Dibujar e historiar: rituales mestizos en El primer nueva corónica de Felipe Guaman Poma de Ayala", Historia y Espacio. Revista de Estudios Históricos Regionales, Departamento de Historia-Universidad del Valle, núm. 15, 1994, Cali, pp. 175-203.

_. "La suerte de lo andino, sus saberes y poderes. Adivinación y mestizaje en el norte de Potosí, Bolivia", tesis de maestría en Historia 
Andina, FLACsO-Universidad del Valle, Cali, Colombia, 1994.

- "Ritual, símbolo y práctica", Brasilia, 1996, inédito.

_ "Estructura y cambio social en una teoría de la práctica", Brasilia, 1996, inédito.

—_- "Los indios están todos muertos. Negación, ocultamiento y representación de identidades étnicas en Santiago del Estero, noroeste argentino", Anuário Antropológico, Tempo Brasileiro, núm. 96, 1997a, Río de Janeiro, pp. 145-155.

"Los indios están todos muertos" en Filosofía en el noroeste argentino, Facultad de Humanidades-Universidad Nacional de Catamarca/Secretaría de Ciencia y Tecnología, Catamarca, 1997b.

- "Identidades y diferencias. Las complejidades identitarias subalternas en las sociedades nacionales" en Hacia el fin del milenio. $V$ Jornadas Nacionales de Filosofía del Noroeste Argentino, Facultad de Humanidades-Universidad Nacional de Salta/Víctor Manuel Hanne Editor, Salta, 1997.

, "Las políticas de los modos del representar en la construcción de las identidades regionales. Los santiagueños en la hegemonía nacional" en Adrián Scribano (ed.), Red de Filosofía y Teoría Social. Segundo Encuentro, Universidad Nacional de Catamarca/Secretaría de Ciencia y Técnica, Catamarca, 1997.

$\longrightarrow$, "Indios muertos, negros invisibles. La identidad 'santiagueña' en Argentina”, tesis de doctorado en Antropología Social, Universidad de Brasilia, Brasil, 1999, en CD-ROM, Equipo Naya/Instituto de Antropología/Universidad de Buenos Aires, Buenos Aires, 2001.

- "Reclinando la clínica. Clínica, crítica y estética”, Santiago de Cali, 2002, inédito. , "La radicalidad cognitivo-comunicativa de lo estético y las ciencias sociales. Relecturas de la Critica del juicio de Kant", Santiago de Cali, 2002, inédito. Los escenarios de la comunicación y de la ciudadanía", Interaf̧ôes, Revista Internacional de Desenvolvimento Local, Universidade Católica Dom Bosco, vol. 4, núm. 6, marzo de 2003, Campo Grande, Brasil, pp. 17-45.

, "El extranjero del vidrio. Estéticas sociales y modernidad", Santiago de Cali, 2003, inédito.

, "Cuerpo, prácticas sociales y modernidad. Tecnologías y representaciones de la corporalidad en la transformación europea, siglos XVI al XVII", Guillermo de Ockham, vol. 7, núm. 1, enero-junio de 2004, Universidad de San Buenaventura, Cali, pp. 43-58.

, "Una modernidad social inaudita e invisible en la trama intercultural latinoamericano-caribeña" en F. López Segrera, J. L. Grosso, A. Didriksson y F. J. Mojica (coords.), América Latina y el Caribe en el siglo XXI. Perspectiva y prospectiva de la globalización, Editorial Miguel Ángel Porrúa/Red Latinoamericana de Estudios Prospectivos/UsB Cali/Editorial Temas/Universidad Autónoma de Zacatecas/UNAM, México y Santiago de Cali, 2004.

—, "Cuerpo y modernidades europeas. Una mirada desde los márgenes", Santiago de Cali, 2005, inédito.

—, "Lo público, lo popular. Pliegues de lo político en nuestros contextos interculturales", Santiago de Cali, 2005, inédito.

-Hobart, Mark, "Who do You Think you Are? The Authorized Balinese" en Richard Fardon (org.), Localizing Strategies, Westview, Los Ángeles, 1990.

-Hulme, Peter, Colonial Encounters, Methuen, Nueva York, 1986.

-Kapferer, Bruce, "From the Periphery to the Center: Ethnography and the Critique of Anthropology in Sri Lanka" en Richard Fardon (org.), Localizing Strategies, Westview, Los Ángeles, 1990. 
-López Segrera, F, J. L. Grosso, A. Didriksson y F. J. Mojica (coords.), América Latina y el Caribe en el siglo XXI. Perspectiva y prospectiva de la globalización, Editorial Miguel Ángel Pornúa/Red Latinoamericana de Estudios Prospectivos/USB Cali/Editorial Temas/Universidad Autónoma de Zacatecas/Unam, México y Santiago de Cali, 2004.

-Memmi, Albert, The Colonizer and the Colonized, Beacon Press, Boston, 1965.

-Nandy, Ashis, The Intimate Enemy, Oxford University Press, Delhi, 1983.

-Nietzsche, Friedrich, La genealogía de la moral. Un escrito polémico, Alianza, Madrid, 1986 (1887).

-O'Gorman, Edmundo, La invención de América, FCE, México, 1984.

-Pagden, Anthony, The Fall of Natural Man. The American Indian and the Origins of Comparative Ethnology, Cambridge University Press, Cambridge, 1982.

-Pratt, Mary Louise, Imperial Eyes. Travel Writing and Transculturation, Routledge, Londres, 1992.

-Ramos, Alcida Rita, "Vozes indígenas. O contato vivido e contado", Anuário Antropológico, Tempo Brasileiro, núm. 87, 1990, Río de Janeiro, pp. 117-143.

, "From Eden to Limbo. The Construction of Indigenism in Brazil" en G. Bond y A. Gilliam (orgs.), The Social Construction of the Past. Representation as Power, Routledge, Londres, 1994.

-Said, Edward, Orientalism, Vintage Books, Nueva York, 1979.

-Sahlins, Marshall, Historical Metaphors and Mytbical Realities. Structure in the early History of the Sandwich Island Kingdom, University of Michigan Press, Ann Arbor, 1981. $\longrightarrow$, Islands of History, University of Chicago Press, Chicago, 1985.

-, How "Natives" think. About Captain

Cook, for Example, The University of Chicago Press, Chicago y Londres, 1995.

-Scannone, J. C. (ed.), Sabiduria popular, simbolo y filosofía. Diálogo internacional en torno de una interpretación latinoamericana, Guadalupe, Buenos Aires, 1984.

-Seed, Patricia. "'Failing to Marvel': Atahualpa's Encounter with the Word", Latin American Research Review, núm. 26, vol. 1, 1991, pp. 7-32.

- "Taking Possession and Reading Texts: Establishing the Authority of Overseas Empires", The William and Mary Quarterly, tercera serie, vol. XIIx, 1992, pp.183-209.

-Sinnott, Eduardo, "La sabiduría mitopoiética en la tradición oral" en J. C. Scannone (ed.), Sabiduría popular, símbolo y filosofía. Diálogo internacional en torno de una interpretación latinoamericana, Guadalupe, Buenos Aires, 1984.

_Spivak, Gayatri, In Other Worlds, Routledge, Londres, 1988.

-Stocking, G. (org.), Colonial Situations, The University of Wisconsin Press, Madison, 1991.

-Todorov, Tzvetan, La conquista de América. La cuestión del Otro, Siglo XXI, México, 1985.

-Turner, Terence, "Representing, Resisting, Rethinking: Historical Transformations of Kayapo culture and anthropological Consciousness" en G. Stocking (org.), Colonial Situations, The University of Wisconsin Press, Madison, 1991. -White, Hayden, Tropics of Discourse, The John Hopkins University Press, Baltimore, 1978. 